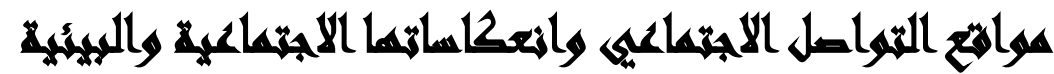

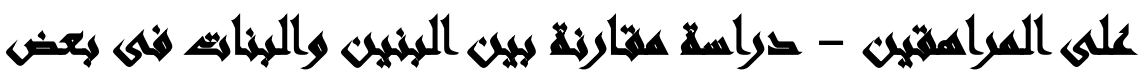 \\ المسارس المسهمي اللغاهي}

[1T]

هبه صالح أبو سريع|(')- مصطفى مرتضى على محمود(Y)-- محمد محمود محمد حسن(r)

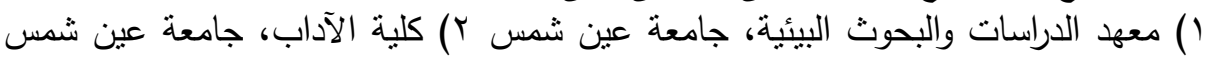
ب) المعهد العالى للخدمة الاجتماعية بالقاهرة

\section{(1)}

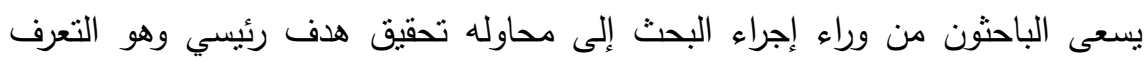

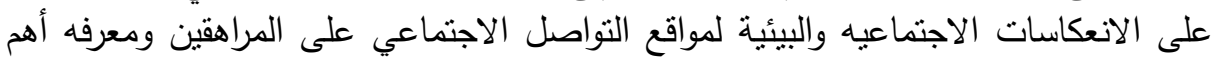

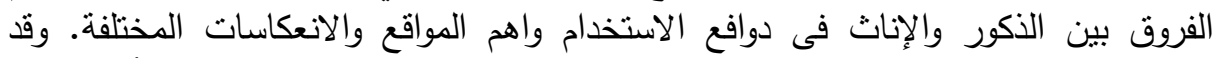

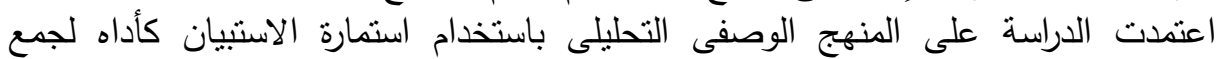

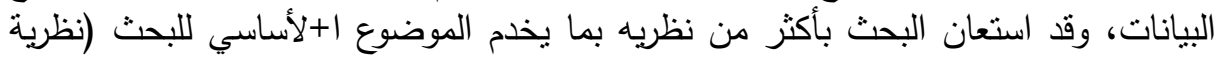

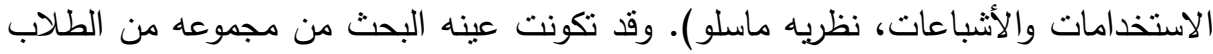

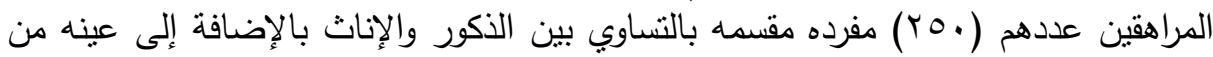

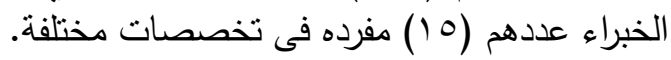

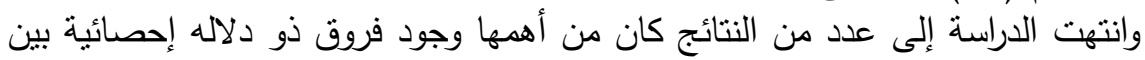

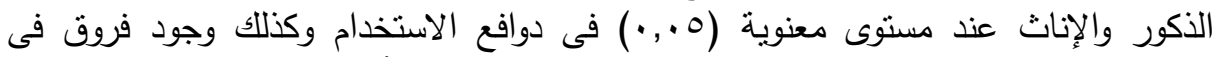

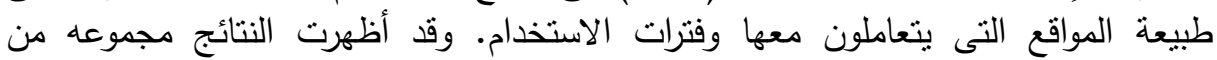

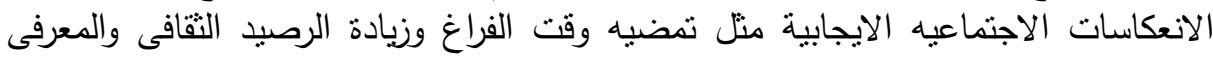
وبعض الانعكاسات الاجتماعيه السلبية مثل إهمال القراءة والإطلاع وإهدار الوقت وفئ ووسيلة لانتشار بعض السلوكيات الغير مرغوبة. كما أظهرت النتائج بعض الإن الانعكاسات البيئية

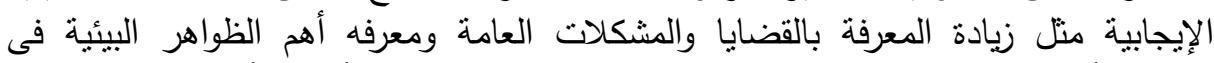

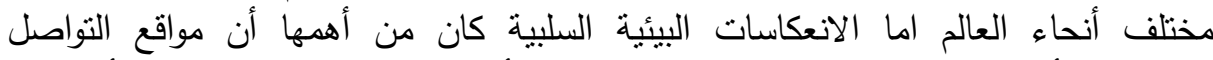

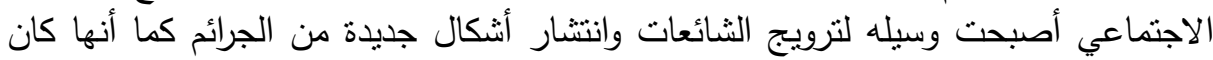

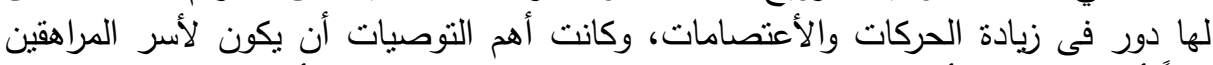

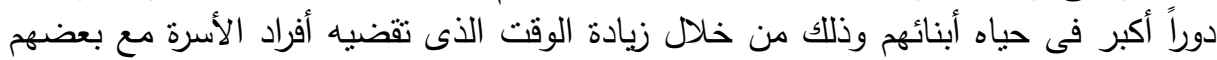
البعض، والاستماع إلى المراهقين بشكل أكبر والنظر إلى احتياجاتهم ومحاوله حل مشكلاتهم،

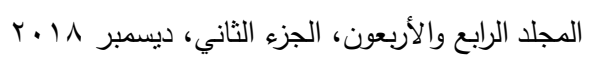


وأن يكون للمراهق صوت مسموع داخل أسرته بدلاً من هروبه من حياته الواقعية إلى العالم

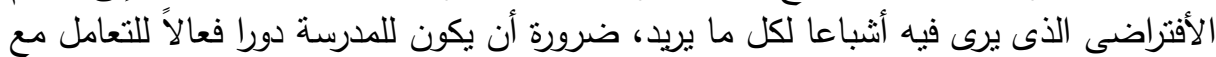

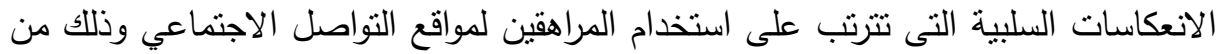

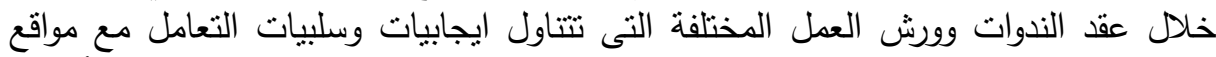

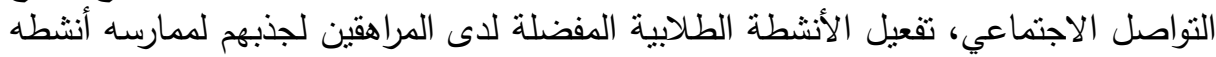

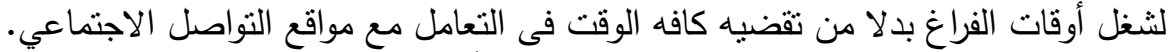

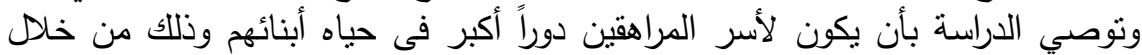

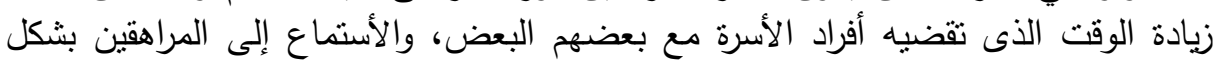

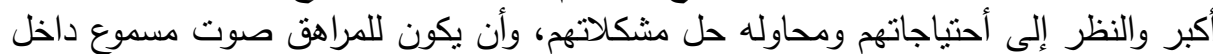

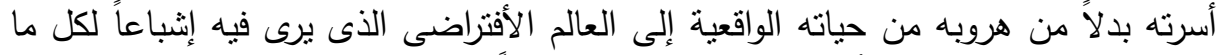

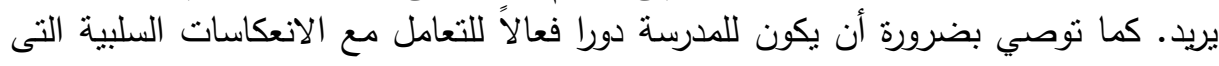

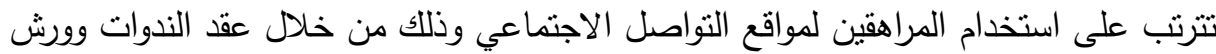

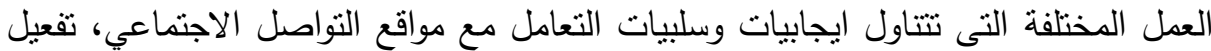

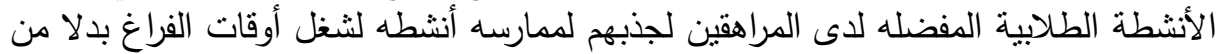

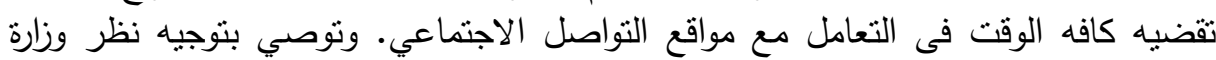

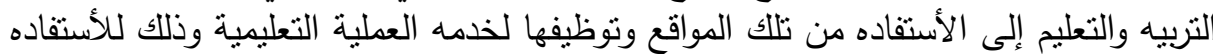

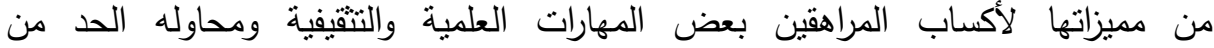

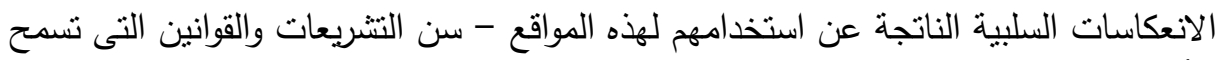
للأجهزة الرقابية بالتعامل مع هذه المواقع واستخدام سلطتها فى منع المواقع الغير مناسبة.

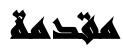

شهد أواخر القرن العشرين وحتى الآن نهضة شاملة فى قطاع تكنولوجيا الاتصالات والمعلومات والإعلام الرقمي الذى عزز من مرونة وسهولة التواصل بين البشر، ومع دخول الإنترنت إلى حياتتا تغيرت العديد من المفاهيم المتعارف عليها فى التعاملات اليومية بين الأفراد. فوجود شبكة الإنترنت والتى أصبحت منوفرة فى كل بيت وفيى كل مكان زاد من أهمية الهية هذا التغيير وجعلته بلامس جميع نواحى الحياة الأجتماعية والبيئية والنفسية بل والجسدية أيضاً للأفراد وتركت أثراً ليس قليلاً فى طريقة تعامل الأفراد مع هذه التكنولوجيا.

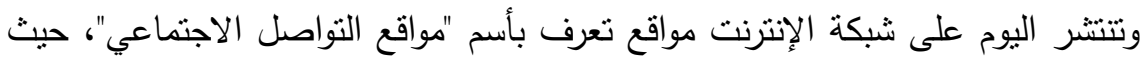

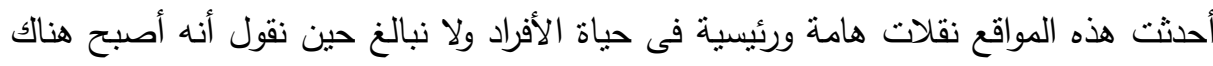

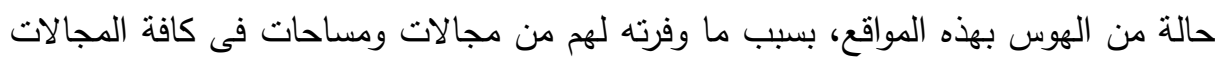

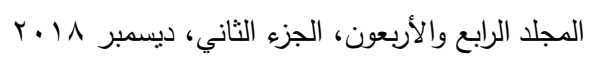


والأهتمامات والميول وكذلك تسهيل هذه المواقع التواصل السمعى والمقروء والمكتوب بين الأفراد مما مهد لهم الطريق لبناء جسور التفاعل. وقد مست مواقع التواصل الاجتماعي جميع فئات وشرائح وطبقات المجتمع، ومن أكثر

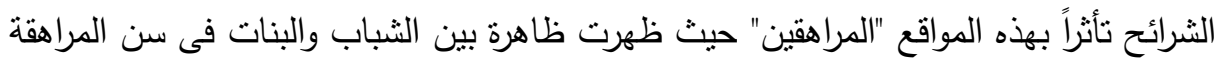
وهى الأفتاح على العالم الخارجى عن طريق مواقع التواصل الاجتماعي على شبكة الإنترنت

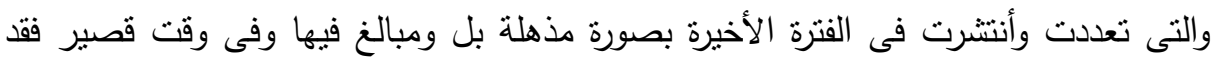

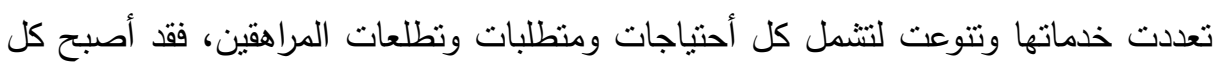
شىء متاح أمام المراهقين فى تعاملهم مع هذه المواقع ولا نوجد مهنوعات أو محاذير لأي

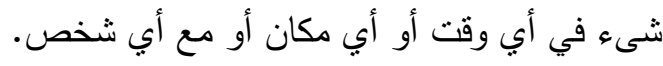

\section{And ILAR}

تتهد مجتمعاتتا الإنسانية فى الآونة الأخيرة تقدم سريع ومتلاحق فى تكنولوجيا

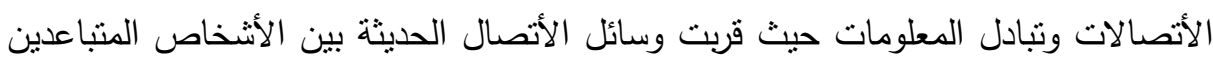
جغرافيا وجعلت العالم يبدو كقرية صغيره من حيث سهوله التواصل وتبادل المعلومات والخبرات والأفتاح على العالم الخارجى وبذلك فرضت هذه الوسائل نفسها على حياتتا دون استئذان وأصبحت جزء لا يستهان به فى حياه المجتمعات الإنسانية بكافه فئاته وشرائحه

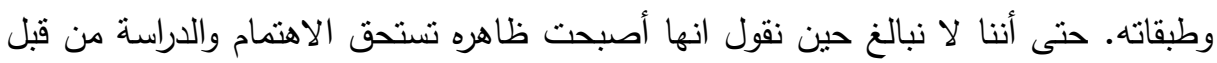

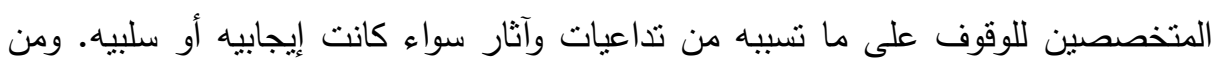
أهم وسائل الأتصال الحديثة التى أصبحت جزء لا يتجزأ من حياتتا اليومية بكافه جوانبها تلاعيات وأنشطتها (شبكه الإنترنت) بما تضمنه من مواقع وتطبيقات وبرامج والتى يعتبر من أهمها لأهال مواقع التواصل الاجتماعي التى ساعدت على التواصل بين البشر دون حدود زمانيه أو مكانيه

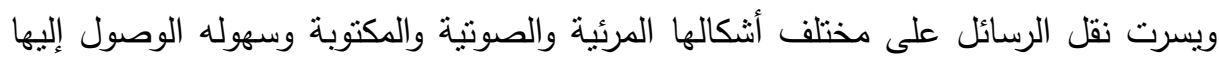
من أى مكان فى العالم خاصة بعد انتشار الكمبيوترات المحمولة والهواتف الذكية المتصلة بشبكه الأنترنت. وهذا ما تؤكده الأحصائيات الخاصة بمستخدمى مواقع التواصل الاجتماعي

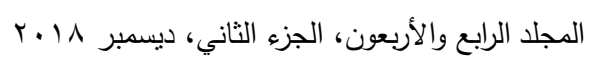




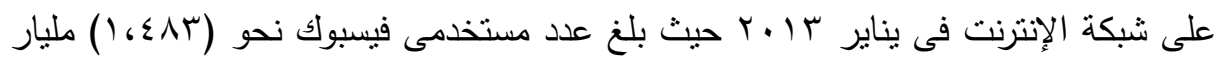

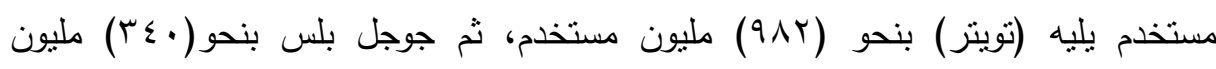

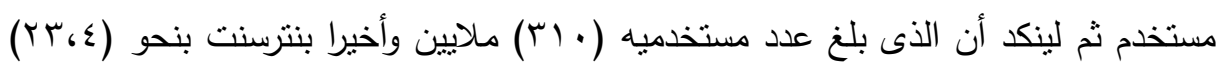

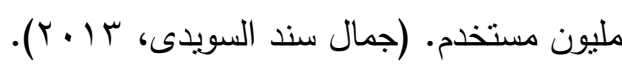
أما بالنسبه لجمهورية مصر العربية فهنالك تزايد ملحوظ فى استخدام شبكه الأنترنت ومواقعها المختلفه وهذا ما أكدته بعض الأرقام الأحصائيه الصادره عن الجهاز المركزى للتعبئه

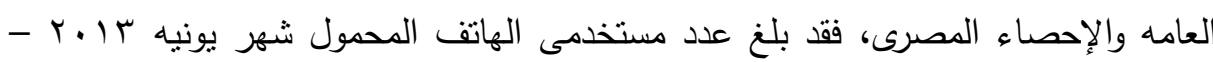

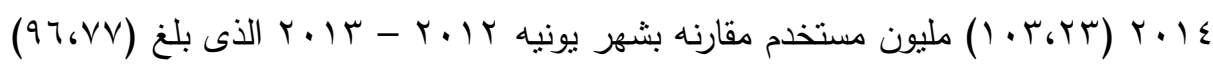

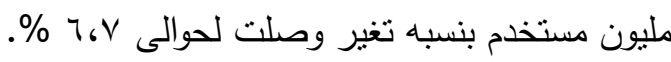

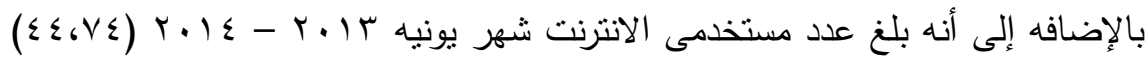

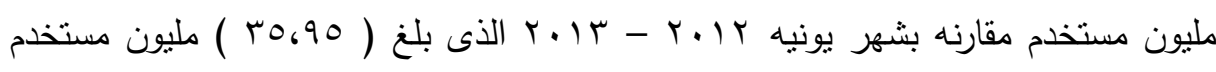

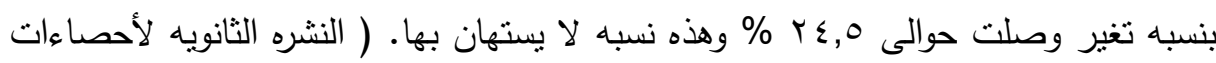

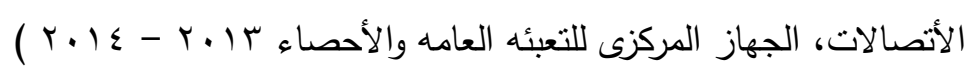

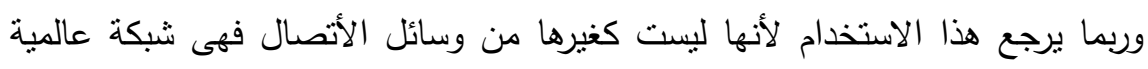
يستطيع المستخدم لها من امام شاشه صغيره التجول عبر العالم من شرقه لغربه، ومن شماله لجنوبه كما ادى سهوله استخدام خدمات هذه الثبكه وتتوعها من بين (منتديات محادثه - بريد

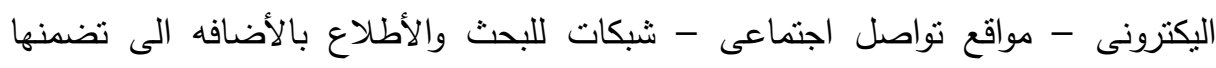

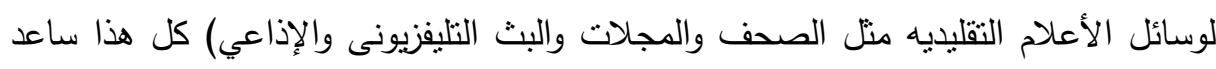
فى استقطاب هذه الثبكه العجية لنسبة عالية من المستخدمين من كافه الأعمار والفئات والمستويات الثقافيه والعلميه والاجتماعيه. وبالرغم من ان الأنترنت يستخدمه الكبار والصغار

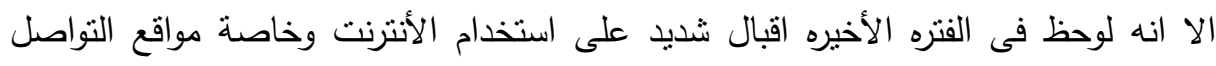

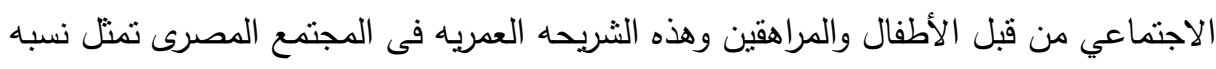
لا يستهان بها من جمله عدد السكان فقد وصل عدد السكان فى الثريحه العمريه التى تنراوح

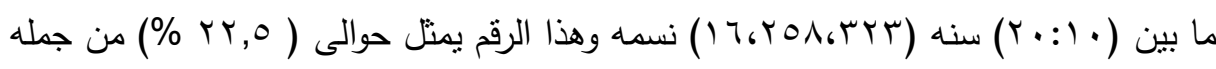

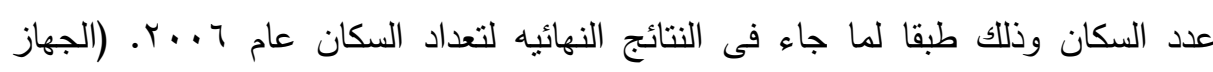

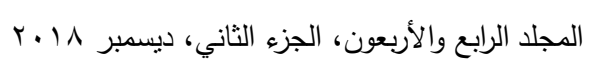




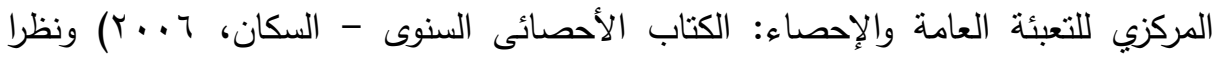
لأهمية هذه المرحلة فى عمر الأنسان حيث تتشكل فيها جوانب الثخصيه وتصقل فيها المهارات والأتجاهات كان من الضرورى دراسه العلاقه بين استخدام المراهقين لثبكه الأنترنت وخاصه مواقع التواصل الاجتماعي بعد ان اصبح استخدامها من قبل هذه الثريحة العمريه

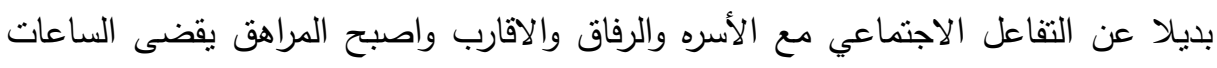

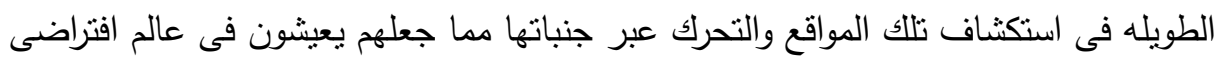
غير واقعى ويعزز لايهم العزله والميل للوحده مما يقلل من فرص التفاعل والنمو الاجتماعي لفي والأنفعالى والنفسى لديهر.

\section{تمساولايت الهمبه}

يعتبر التساؤل الرئيسي لهذه الدراسة: "ما الانعكاسات الاجتماعيه والبيئية لمواقع التواصل الاجتماعي على المراهقين؟" وينبثق من هذا التساؤل مجموعة من التساؤلات الفرعية وهى: - الفئ

1-ما دوافع استخدام المراهقين لمواقع التواصل الاجتماعي؟

r-ما أهم مواقع التواصل الاجتماعي من وجهه نظر المراهقين؟ r-هل نوجد فروق بين المراهقين (الذكور - الإناث) فى دوافع استخدام مواقع التواصل الاجتماعي?

ع- ما مدى وجود فروق بين المراهقين (الذكور - الإناث) فى طبيعة المواقع التى يتعاملون مeها?

ه- ما مدي وجود فروق بين المراهقين (الذكور - الإناث) فى فترات استخدام مواقع التواصل

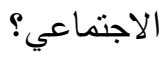

؟- ما الانعكاسات الاجتماعيه البيئية الناتجة عن استخدام المراهقين لمواقع التواصل

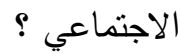


V- ما الدور الذى تقوم به اللأسرة مع المراهقين لمتابعة استخدامهم لمواقع التواصل الاجتماعي?

^- ما التصور المقترح لمواجهة الانعكاسات السلبية الناتجة عن استخدام المراهقين لمواقع

$$
\text { التواصل الاجتماعي? }
$$

\section{أهساهش التراسة}

يتمنل الهدف الأساسى لهذه الدراسه التعرف على الانعكاسات الاجتماعيه والبيئيه

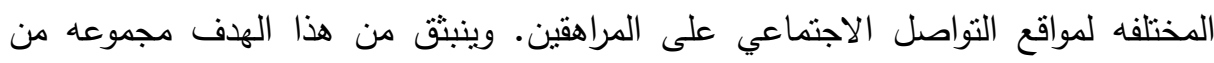

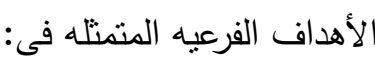
1- التعرف على دوافع استخدام المراهقين لمواقع التواصل الاجتماعي. r-التعرف على أهم مواقع التواصل الاجنماعي من وجهه نظر المراهقين.

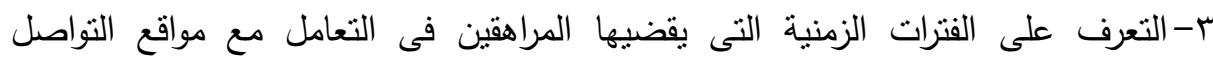
الاجتماعي. ع- التعرف على الفروق بين المراهقين (الذكور والإناث) فى دوافع الاستخدام. ه- التعرف على الفروق بين (الذكور والإناث) فى طبيعة المواقع التى يتعاملون معها.

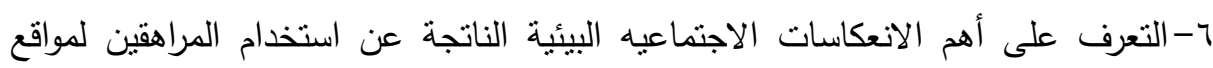

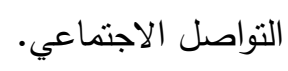

V-التعرف على الدور الذى تقوم به الأسره مع المراهقين لـتابعة استخدامهم لمواقع التواصل الاجتماعي.

^- وضع تصور مقترح لمواجهة الانعكاسات السلبية الناتجة عن استخدام المراهقين لمواقع

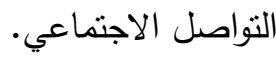

\section{أهمبه الصواسمة}

أصبحت شبكه الإنترنت فى الآونة الأخيرة من المؤثرات بالغه الأهمية فى حياه البشر

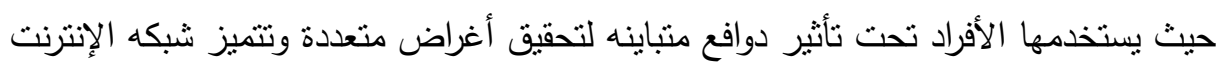

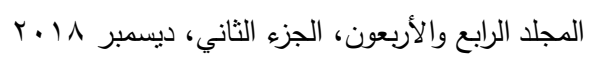


بأنها أداه اتصاليه ذات طابع اجتماعى أحدثت تغيير بالغ الأثز فى حياتنا اليوميه ومن ثم

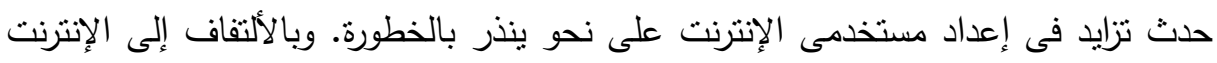

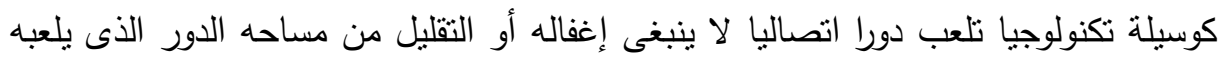

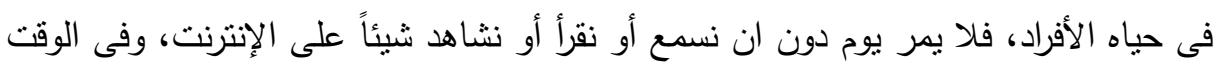

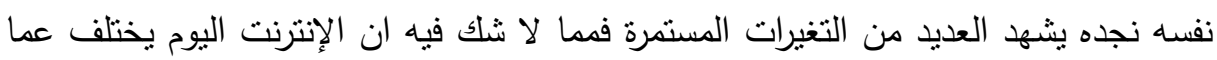

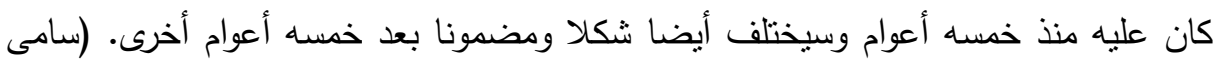

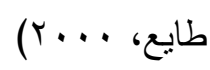

\section{همطلحاهي الهمبه}

شبكة الإنترنت: إن كلمة الإنترنت لم تكن معروفه فى اللغة الإنجليزية قبل مسماها بل

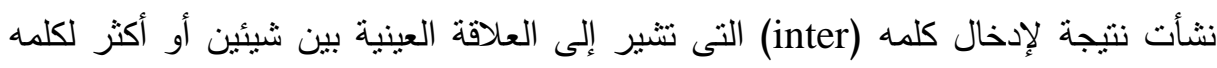

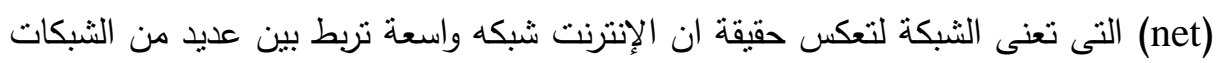

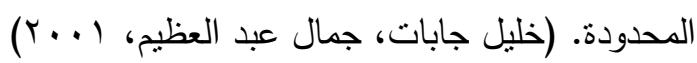
ويُعرَف جاجنون (Eric Gagnon) الإنترنت بأنه طريق سريع يربط بين الدول وبعضها

البعض ويمد الأفراد بالمعلومات. (Eric Gangon, 1996) مواقع التواصل الاجتماعي: هى تلك المواقع الموجودة على الإنترنت والتى تتيح لمستخدميها التواصل المرئى والصوتى والمكتوب وتبادل الصور والمعلومات وغيرها من

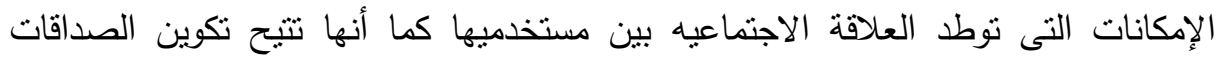
والمشاركة بين الأصدقاء سواء الفيديو أو الصور أو المنشورات المكتوبة والتعليق عليها ونشرها

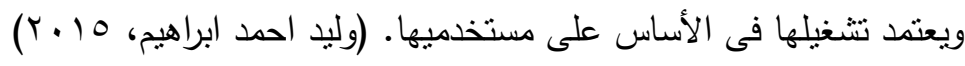
الانعكاسات الاجتماعيه: ويعنى بها التأثيرات المختلفة الإيجابية/السلبية الناتجة عن استخدام تطبيقات الثثرة الرقمية على البيئة الأجتماعية، وبخاصة تأثثراتها على منظومة القيم

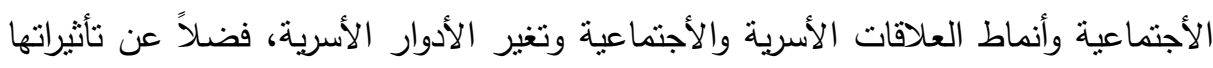

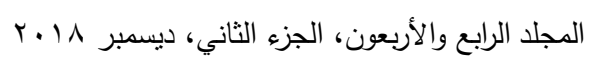


على السستوى المعرفى والسلوكى للأنسان، وما ينتج عن تلك الثأثيرات من تغير فى أسلوب

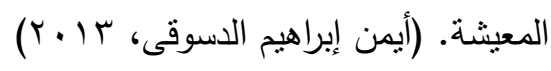

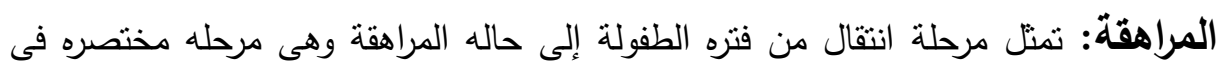
العديد من المجتمعات والتى من خلالها يقوم أغلب الأطفال بتعلم أدوارهم الاجتماعية والوظيفية العالية

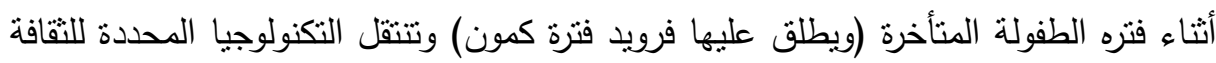

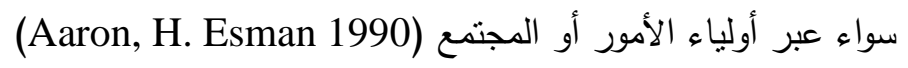

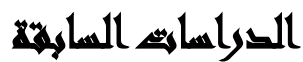

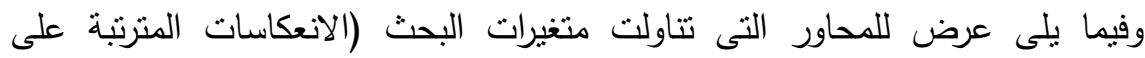

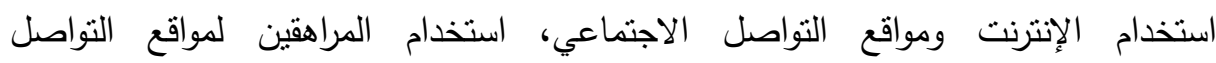

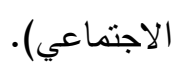
محور اهتم بالانعكاسات المترتبة على استخدام الإنترنت ومواقع التواصل الاجتماعي: دراسة وليد أحمد إبراهيم (10 + ب): استخدامات الأطفال الصم لمواقع التواصل الاجتماعي الإسي

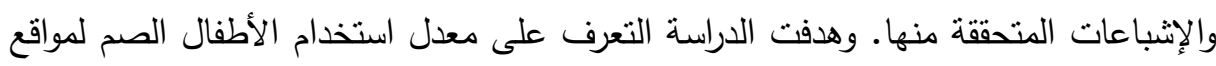

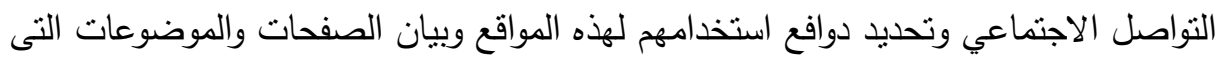

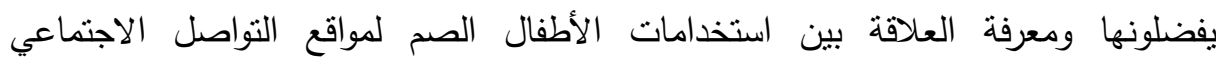

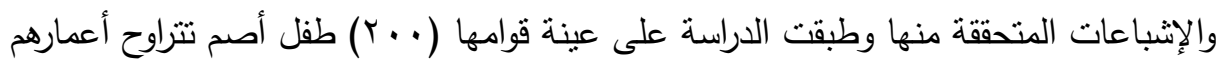

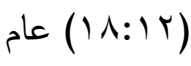
وقد توصلت الدراسة إلى مجموعة نتائج من أهمها: أن أكثر مواقع التواصل الاجتماعي

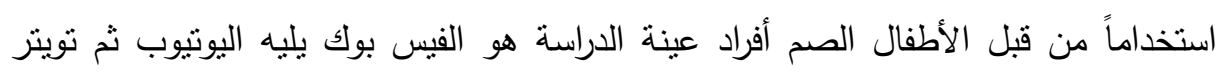

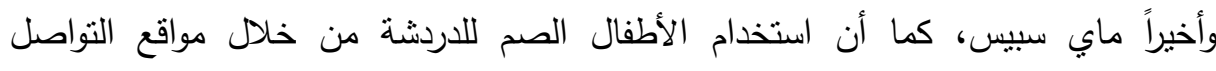
الاجتماعي بكثافة يجعلهم أكثر راحة ومستقرين نفسياً. 
دراسة الشيماء محمد أحمد (10 ب): تعرض المراهقين للصفحات الإسلامية على الفيس بوك وعلاقته باكتساب المعلومات الدينية. وتهدف هذه الدراسة إلى التعرف على الدور الذى الذى

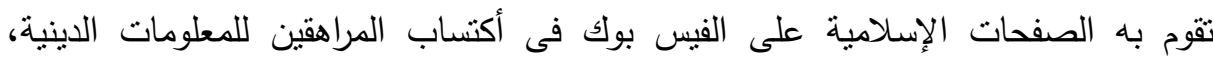

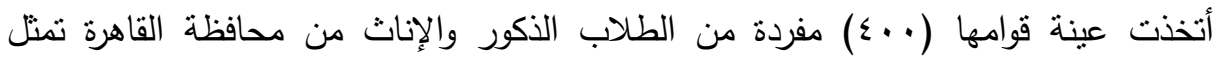
التوزيع المتساوى على الجامعات المصرية الحكومية والخاصة. وقد توصلت الدراسة لمجموعة من النتائج من أهمها: أن المراهقين أفراد العينة يتعرضون

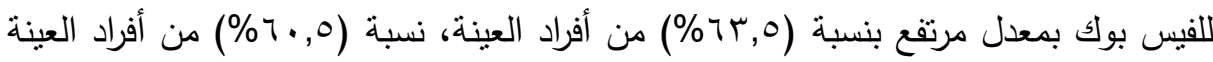
ينقون بدرجة متوسطة فى المعلومات الدينية التى تتشرها صفحات الفيس بوك الإسلامية،

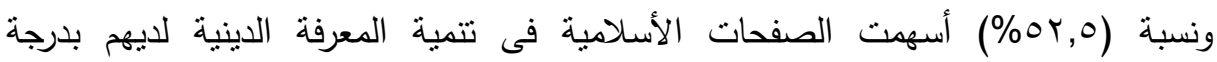
متوسطة.

دراسة هند نور الدين محمد عفيفى (\{ ا ب؟): الآثار الاجتماعيه السلبية الناجمة عن سوء

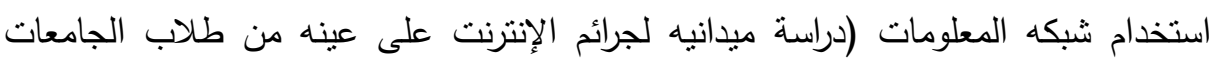
المصرية). وهدفت هذه الدراسة للتعرف على آثار سوء استخدام شبكه المعلومات الدولية ودور تللك الآثار فى التعرض وارتكاب الجرائم الأكترونيه على شبكه الإنترنت، نم اختيار عينه عمديه قوامها ( . . r) مفرده من طلاب الجامعات المصرية. وقد أظهرت نتائج الدراسة عده نقاط أهمها: ارتفاع نسبة الذكور عن الإناث فى عداث السنوات وطول فترات الاستخدام وظهر ارتفاع نسبه الإناث فى عدم استخدام بياناتهن الحقيقية

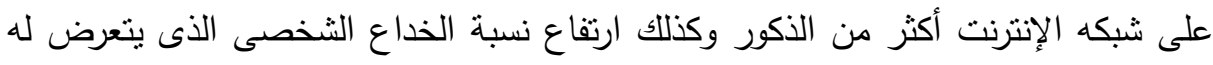
الثباب وحالات القرصنة والاختراق أثناء التعامل مع الإنترنت. محور اهتم باستخدام المراهقين للانترنت ومواقع التواصل الاجتماعي: دراسة جيمس، لابا (James, Libba: 2014) بعنوان "رباط مستمر فى العالم الأفتراضى - استخدام الفيس بوك فى حزن المراهقين". تعليق على الدراسة: الهدف الأساسى من هذه الدراسة هو الحصول على فهر فهم أفضل لتجربة

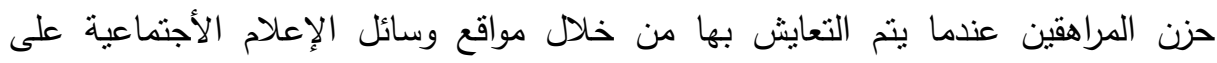

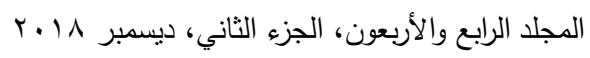


الإنترنت وخاصة الفيس بوك. وقد أظهرت نتائج الدراسة أن جميع مفردات عينة الدراسة

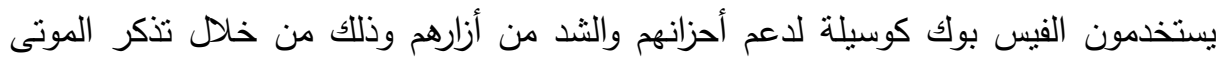

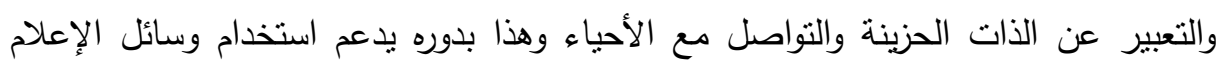

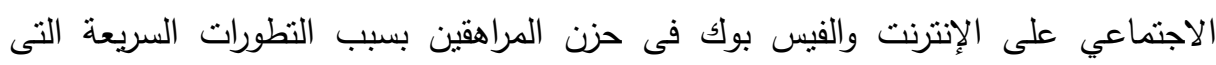
تحدث يومياً فى التكنولوجيا والإعلام الاجتماعي على الإنى الإنترنت دراسة: أكنا أديل، وول التكيون (Ikenna Adiele, Wole Olatakun 2014 بعنوان: "أنتثار أدمان الإنترنت بين المراهقين وكيفية الحد منه".

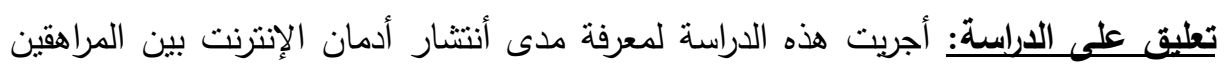

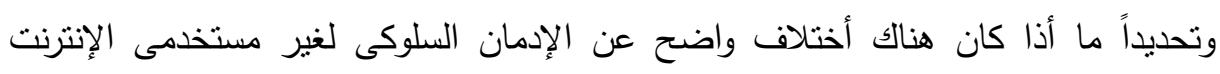

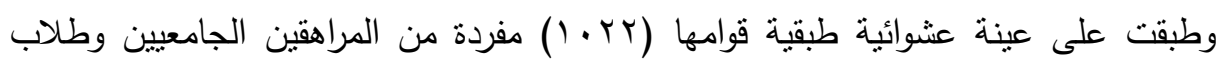

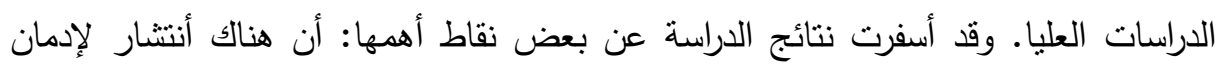

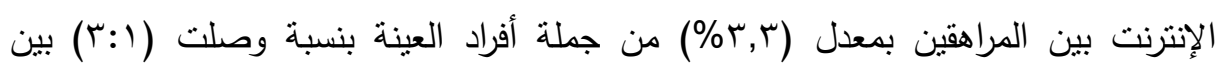

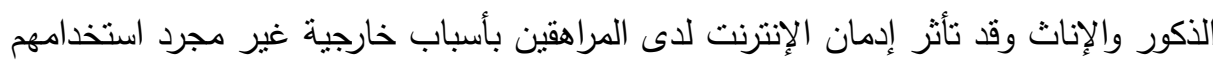

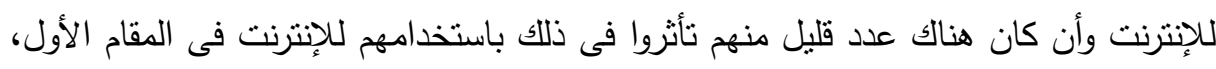

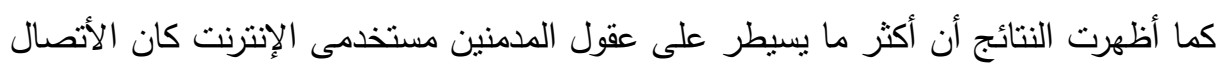

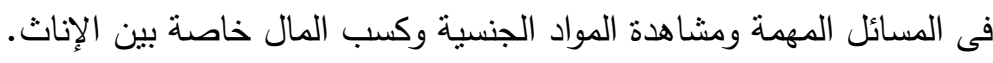

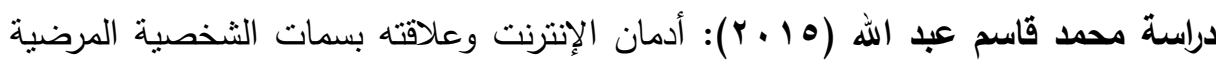

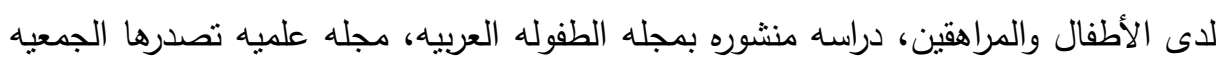

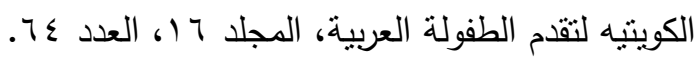

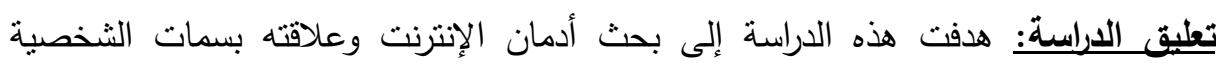

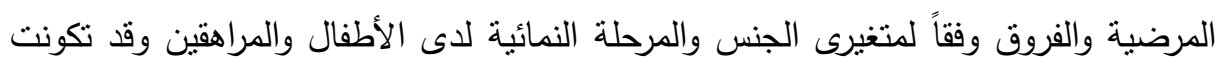

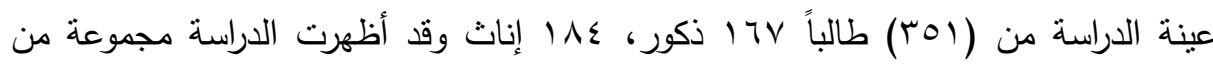

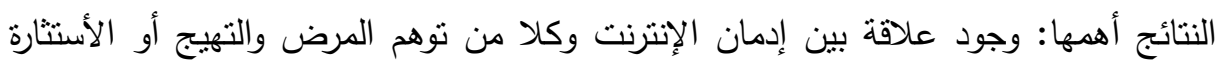

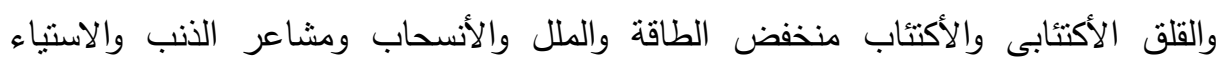
والأنحراف السيكوبانى والوهن النفسى وعدم الكفاية النفسية. 


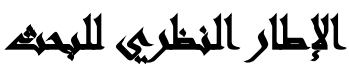

إن الفرد يميل إلى تحقيق النوازن أو الأتساق أو الأنسجام - بصرف النظر عن

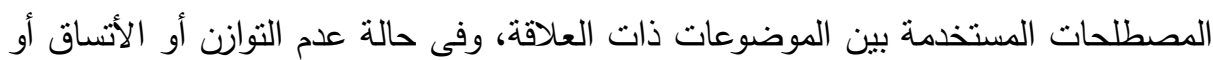

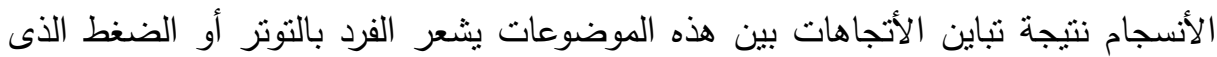
يدفعه إلى محاولة تغيير أتجاهه فى الجانب الذى يحقق له التوازن أو عدم الأتساق ويجنبه التوتز والقلق الناتج عن هذا التباين.

وفى مجال استخدام وسائل الإعلام كحالة تطبيقية، سنجد أن الفرد يميل إلى التعرض

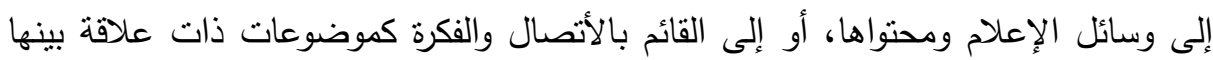

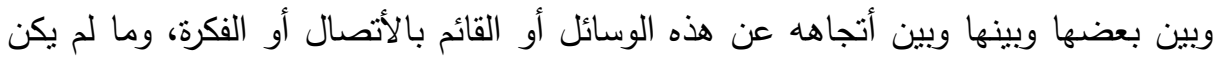
هناك توازن فى محصلة الأتجاهات نحو هذه المفردات ذات العلاقة، سنجد أن استخدامه لهات

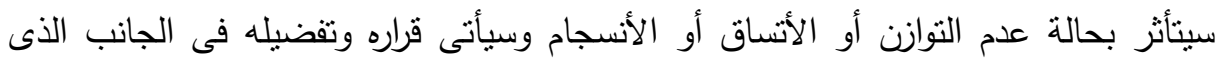

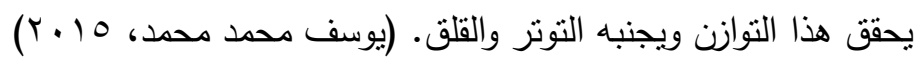
وفى هذا الصدد تهنم نظرية الاستخدامات والأشباعات بدراسة الأتصال الجماهيرى دراسة

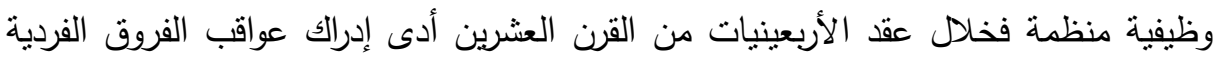

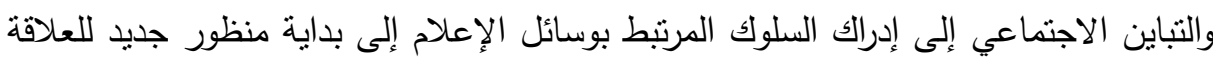

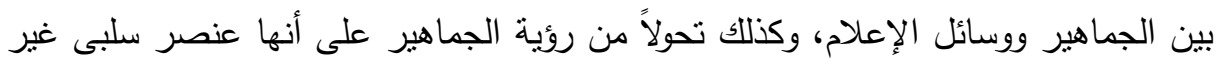

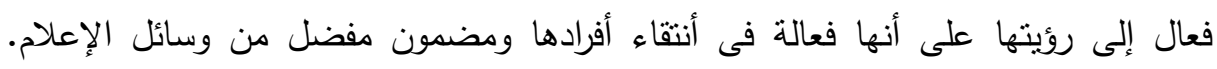

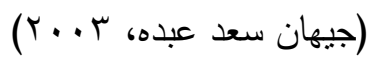

يرى بعض الباحثين أن أية محاولة لدراسة الأتجاهات البحثية والنظرية فى التأثيرات

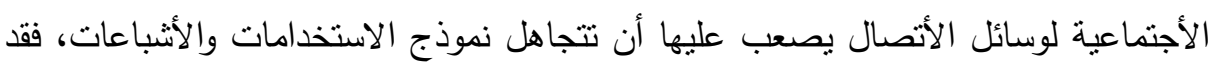

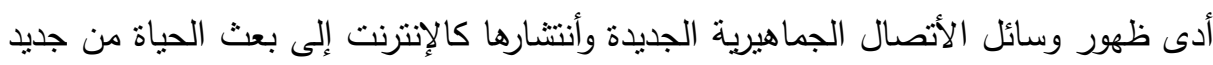

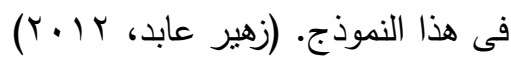

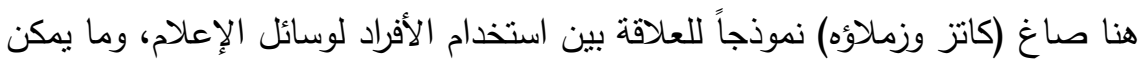

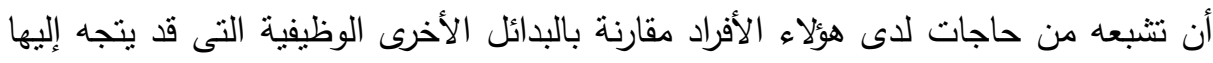

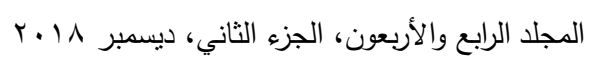


الأفراد لتلبية الحاجات، مثل الأنشطة الثقافية الأخرى، فهو يرى أن لدى كل فرد عدد من العوامل الأجتماعية والنفسية التى تولد حاجات معينة للفرد. ومن خلال الأخير يبدأ الفرد فى رسم توقعاته عن تلبية وسائل الإعلام لهذه الأشباعات التهات مقارنة بمصادر أخرى لإشباع هذه الحاجات فيترتب على ذلك أختيار قرار بالأختيار بين

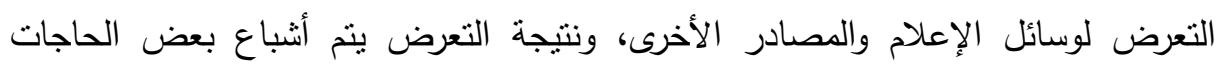

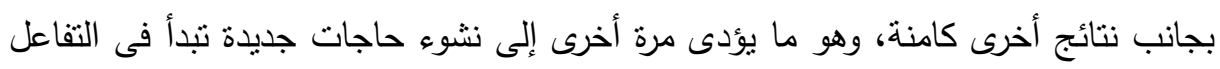

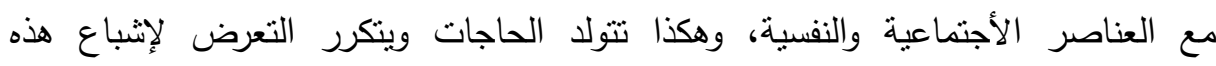
الحاجات . (محمد عبد الحميد محمد، لو 199 ). أسباب ظهور مدخل الاستخدامات والأثباعات: ظهر مفهوم الاستخدامات والأشباعات فى مجال الدراسات الإعلامية كبديل لتلك الأبحاث التى تتعامل مع مفهوم التأثير

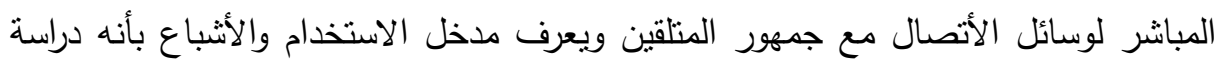

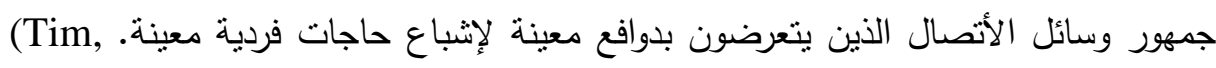
O. Sullivan and others, 1994) وقد أكد كاتز وهو أحد رواد هذا الدذخل أن استخدام وسائل الأتصال يتضح بصورة واضحة حينما نوجه أهتمامنا بما يفعله الجمهور بتلك الوسائل لا حينما نهتم بما تفعله وسائل التل

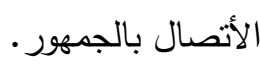

مدى ملائمة نظرية الاستخدامات والأشباعات للبحث الحالى: أن النمو الهائل فى الأل استخدام الإنترنت ومواقع التواصل الاجتماعي خاصة من قبل المراهقين جعل من المناسب استخدام مدخل الاستخدامات والأشباعات فى هذه الدراسة وذلك لعدة أسباب منها:

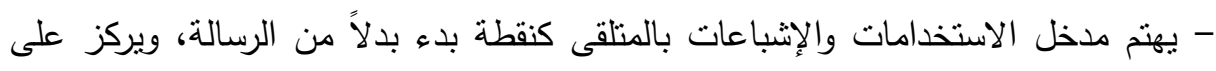

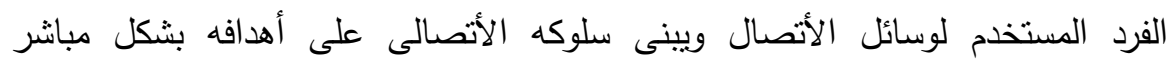

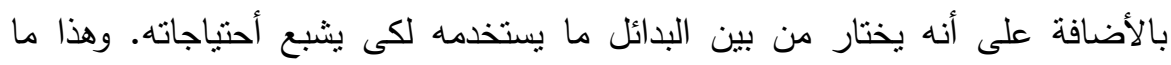

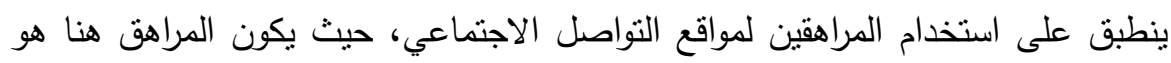

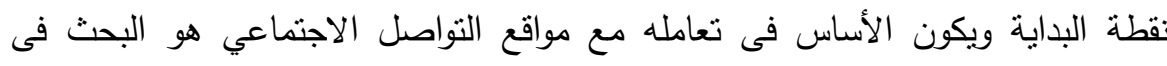


مختلف المواقع عن ما يثبع أحتياجاته هو وتختلف الرغبة فى أثباع حاجات معينه لدى

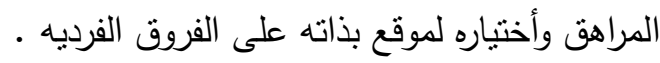

- وكذللك يفترض مدخل الاستخدامات والأثباعات أن جمهور وسائل الإعلام جمهور نشط له له له دوافعه الثخصية والنفسية والأجنماعية لاستخدام الوسيلة الأتصالية وأنه يدرك ما يختاره.

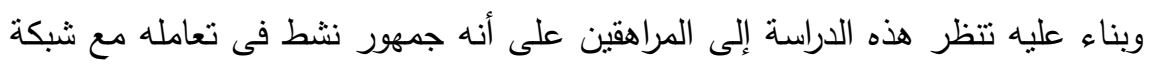

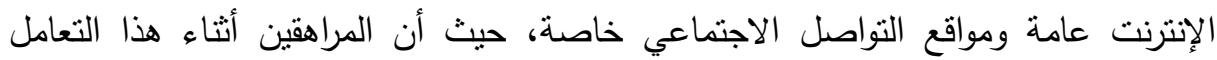
والأتصال يقومون بإرسال وأستقبال مختلف الرسائل التى تنتبع حاجاتهر وتلبى رغئ رغباتهم ومتطلباتهم وتحقق توقعاتهم الثخصية. - أن أحد أهداف نظرية الاستخدامات والإثباعات هو الكثف عن التهاته العلاقة المنبادلة بين دوافع

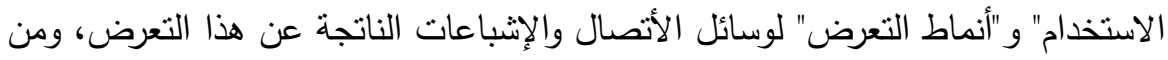

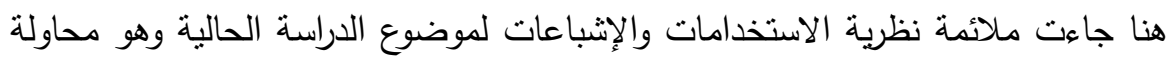
معرفة أسباب ودوافع المراهقين التى تدفعه لاستخدام مواقع التواصل الاجتماعي على الأنى شبكة الإنترنت وتفضيل هذه المواقع على وجه الخصوص عن غيرها من المواقع الأخرى.

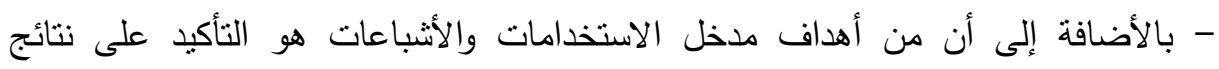

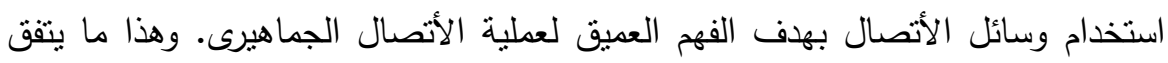
مع أهداف الدراسة الحالية وهو محاولة التعرف على الانعكاسات الأجتماعية البيئية المختلفة الناتجة عن استخدام المراهقين لمواقع التواصل الاجتماعي على شبكة الإنترنت.

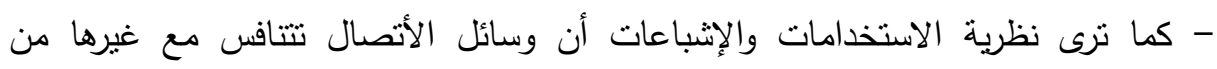
الوسائل لإشباع حاجات الجمهور، فالأفرادهم الذين يختارون محتوى الوسائل بإرادتهم ووفقاً

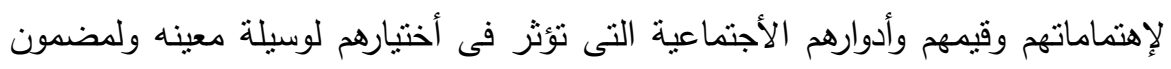

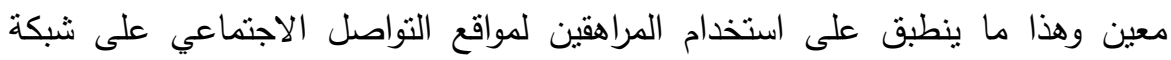
الإنترنت فقد أصبحت هذه المواقع تتافس غيرها من وسائل الأتصال الأخرى منافسة شديدة لثئ

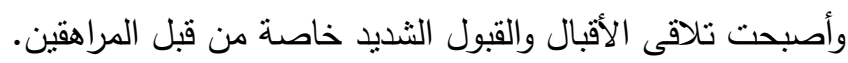


- أثنارت الدراسات التى نتاولت مدخل الاستخدامات والإشباعات أن هناك درجة كبيرة من

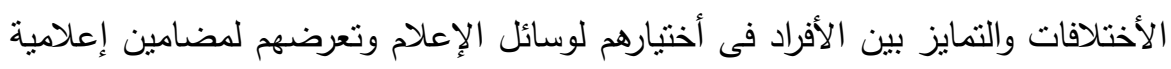

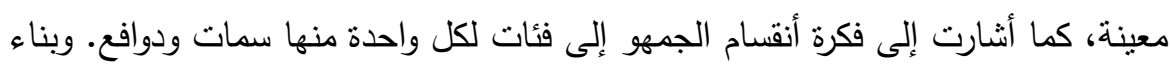

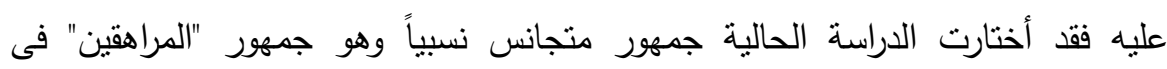

$$
\text { المجنمع المصرى. }
$$

- وكذلك افترض مدخل الاستخدامات والأشباعات أنه يمكن الاستدلال على المعايير التقافية

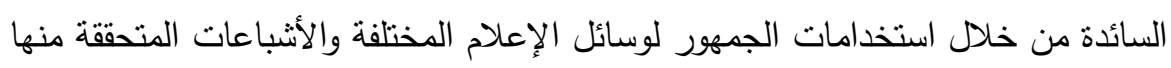

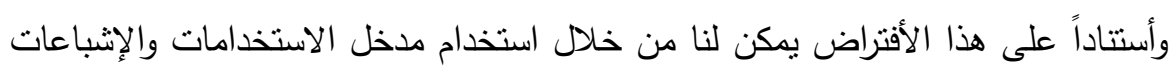

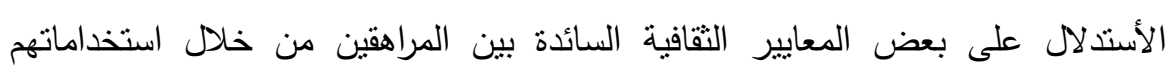
المختلفة لمواقع التواصل الاجنماعي على شبكة الإنترنت.

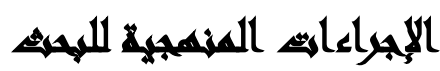

المنهج المستخدم: استعان الباحثون فى معالجة موضوع البحث بمنهج المسح الاجتماعي باستخدام العينة ومستفيدا من معطيات المنهج الوصفى لرصد ووصف وتحليل أبعاد ظاهره استخدام المراهقين لمواقع التواصل الاجتماعي. أدوات البحث: أستخدم الباحثون الأستبيان كأداة لجمع البيانات وقد نم إعداد استمارتي استبيان الأولى خاصة بمفردات العينة من الطلاب المراهقين وكان عدد الأسئله لهذه الأستماره سته وعشرون سؤالا والثانية خاصة بمفردات العينة من الخبراء وكان عدد الأسئله عشره اسئله.

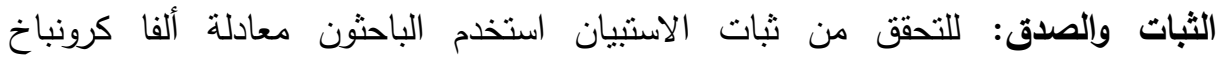
(Alpha Cronbach)

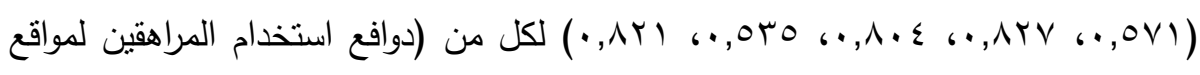

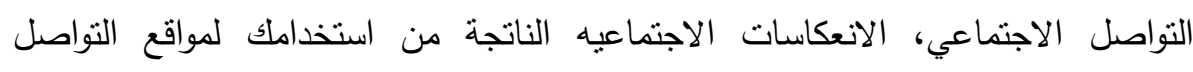

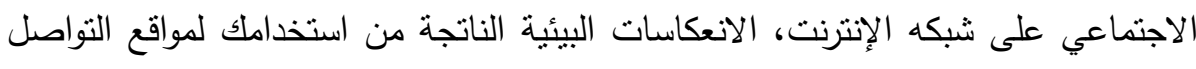

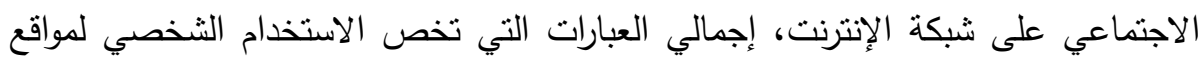
التواصل الاجتماعي، إجمالي العبارات التي تخص الإستئه الإندام العائلي لمواقع التواصل 346

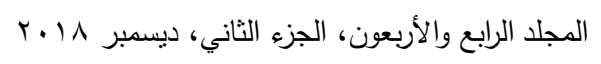


الاجتماعي) على التوالي، وكانت قيمة ألفا لإجمالي الاستبيان (^•^, •) وهي قيم جميعها

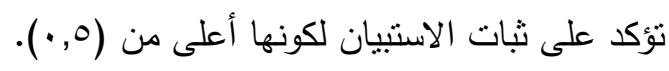

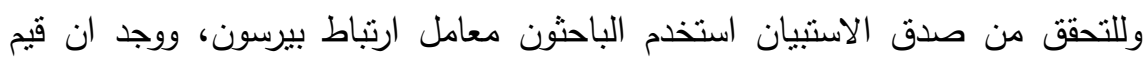

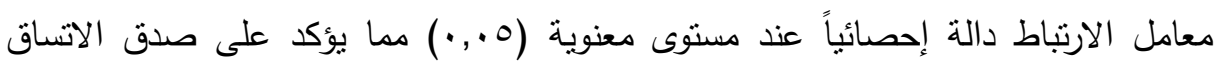
الداخلي لكل من (دوافع استخدام المراهقين لمواقع التواصل الاجتماعي، الانعكاسات

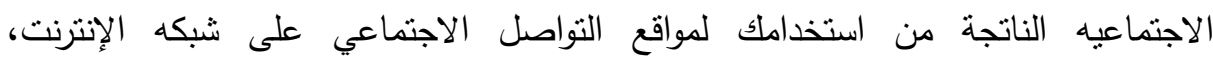
الانعكاسات البيئية الناتجة من استخدامك لمواقع التواصل الاجتماعي على شبكه الإنترنت،

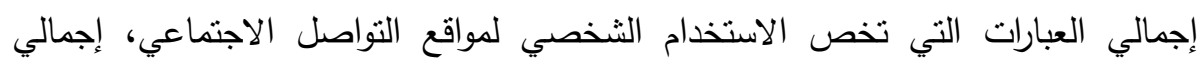

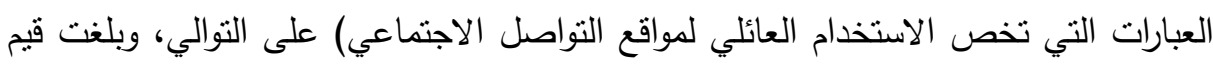

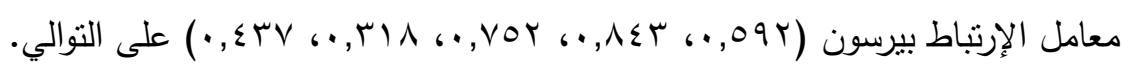
العينة وحجمها: طبق البحث على عينه قوامها (.0. مفرده) من المراهقين بنظام التوزيع المتساوى بين الذكور والإناث وعينه من الخبراء قوامها (10 مفرده) من المعلمين والأخصائيين الاجنماعيين وأساتذة الجامعة. فتره ونطاق التطبيق الميدانى: نم أجراء البحث الميدانى على الطلاب المراهقين الذكور والإناث فى المرحلتين الإعدادية والثانوية فى بعض الددارس الرسمية بمحافظه القاهرة فى لئ

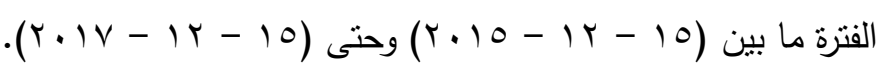




\section{المتائية}

التساؤل الأول: ما هى دوافع استخدام المراهقين لمواقع التواصل الاجتماعي؟

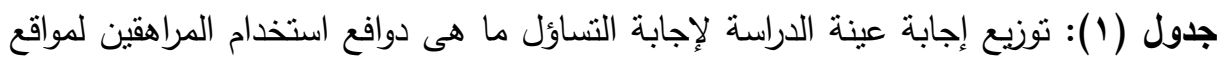
التواصل الاجتماعي؟ لإناع

\begin{tabular}{|c|c|c|c|c|c|c|c|c|c|c|c|c|c|c|}
\hline \multirow{3}{*}{ |المئوجيح |الموس| } & \multicolumn{6}{|c|}{ إناث } & \multirow{3}{*}{ |المتوجي |لمئوي } & \multicolumn{6}{|c|}{ ذكور } & \multirow{3}{*}{ الدوافع } \\
\hline & \multicolumn{2}{|c|}{ نعم } & \multicolumn{2}{|c|}{ أحيانا } & \multicolumn{2}{|c|}{$\gamma$} & & \multicolumn{2}{|c|}{ نعم } & \multicolumn{2}{|c|}{ أحيانا } & \multicolumn{2}{|l|}{$y$} & \\
\hline & $\%$ & ك5 & $\%$ & |ك & $\%$ & |⿹ & & \begin{tabular}{|l|}
$\%$ \\
\end{tabular} & ك & $\%$ & كt & $\%$ & |ك & \\
\hline$V \pi, T$ & 07 & $v$. & $r 0, r$ & $\leqslant \varepsilon$ & $\wedge, \wedge$ & 11 & $V T, T$ & 7. & vo & $Y v, Y$ & | & $\mid r, \lambda$ & 17 & التعرف علمعى الأخبار \\
\hline T & IT & 10 & $\leqslant Y, \varepsilon$ & or & $\leqslant 0,7$ & or & $\varepsilon \cdot, \Lambda$ & $r v, r$ & $r \varepsilon$ & $Y v, Y$ & r & $\{0,7$ & $0 v$ & التكوين رأى حول المثاره \\
\hline $0 \leqslant, \varepsilon$ & 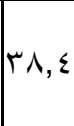 & $\leqslant 1$ & rT & $\varepsilon$. & 9,7 & r & $7 r$ & $\{\wedge, \Lambda$ & 71 & ז4, & Tra & $r \varepsilon, \Lambda$ & ו & 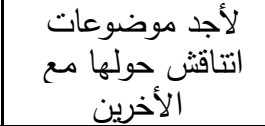 \\
\hline$\wedge \uparrow, \varepsilon$ & 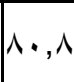 & .1 & 11,5 & $1 \leq$ & $\wedge$ & 1. & $\vee 9,7$ & $V r, 7$ & 94 & IT & 10 & $\varepsilon, \varepsilon$ & in & للتخلص من الملت وقل \\
\hline$\uparrow \Lambda, \wedge$ & $0 v, 7$ & $V T$ & Yr, & rN & $r \cdot$ & ro & $V r, T$ & $T r, \varepsilon$ & VA & $Y Y, \varepsilon$ & YN & $10, Y$ & 19 & فلى وسائل الأن الأعلام \\
\hline $9 \cdot, 1$ & $\Lambda 7, \varepsilon$ & 1.1 & $\Lambda, \wedge$ & 11 & $\varepsilon, \wedge$ & 7 & $9 Y, 1$ & $\Lambda \vee, Y$ & 1.9 & $11, r$ & $1 \leq$ & 1,7 & $r$ & التسلية والتزفيه \\
\hline $07, \varepsilon$ & $\leqslant r, r$ & $0 \leqslant$ & $r 7, \varepsilon$ & $r$ & $\cdot, \varepsilon$ & ros & $\tau \cdot, \varepsilon$ & $\leqslant 9,7$ & TY & $r^{\prime}, 7$ & $r v$ & үA, & ד & أقامه علاقات مع الأخرين \\
\hline$\wedge \Lambda, \varepsilon$ & $\wedge$. & $1 \ldots$ & 17,1 & $r \mid$ & $r, r$ & $\varepsilon$ & $\Lambda \varepsilon$ & V4 & 90 & 17 & $r$. & $\wedge$ & 1. & للتعرف على جلى مل ما \\
\hline $7 \varepsilon$ & $0,\{$ & Tr & $r v, r$ & $\Gamma \varepsilon$ & $r, \varepsilon$ & rN & $v 1, r$ & $09, Y \mid$ & $v \varepsilon$ & $r \leq$ & $r$. & $\mid 7, \wedge$ & rl & اللاردشة مع صداقات \\
\hline ד, & $\leqslant \varepsilon, \Lambda$ & 07 & $V$, & $\mathrm{V}$ & $v, 7$ & $|r Y|$ & $v 1, r$ & 07,1 & v) & rı, & 4 & $1 \leq, \varepsilon$ & $1 N$ & لنشر صورى وأخبارى \\
\hline$\vee \wedge, \wedge$ & $7 \varepsilon \leqslant, \Lambda$ & (1) & r^ & ro & $V, r$ & 9 & $\Lambda r, \Sigma$ & $V Y, \lambda$ & 91 & 19,4 & $r \leqslant$ & $\wedge$ & 1. & 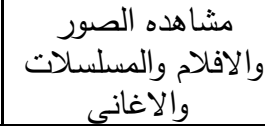 \\
\hline 17 & . & $\cdot$ & rT & $\varepsilon$. & $\varepsilon$. & 0. & $\varepsilon \wedge, \wedge$ & $r v, \tau \mid$ & $\varepsilon V$ & Yr, & YN & $\varepsilon$. & 0. & الألبتعادية أو المدرسبة السلطة \\
\hline
\end{tabular}


أنشارت نتائج الدراسة أن أهم دوافع المراهقين لاستخدام مواقع التواصل الاجتماعي هى:

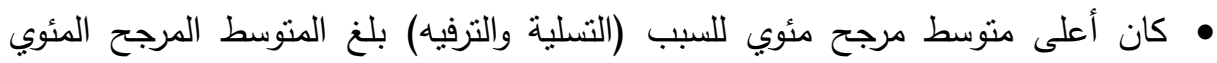

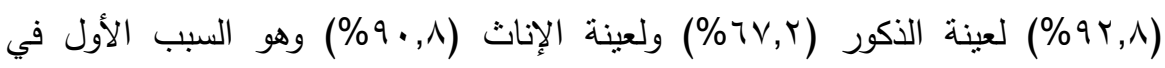
ترتيب الأهمية بالنسبة لأسباب استخدام مواقع التواصل الاجنماعي على شبكة الإنترنت

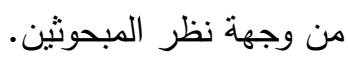
• في الترتيب الثاني للأهمية كان السبب (للتعرف على كل ما هو جديد) بمنوسط مرجح مئوي

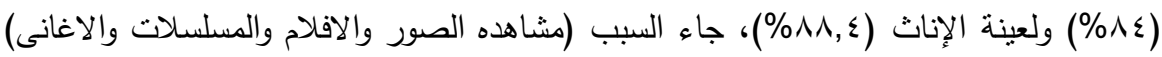

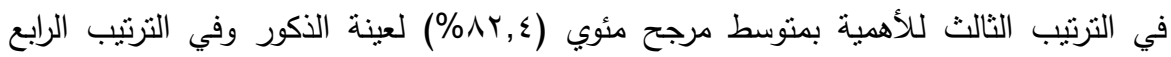

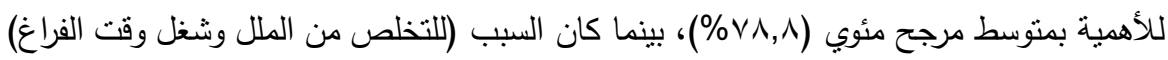

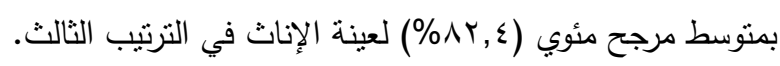

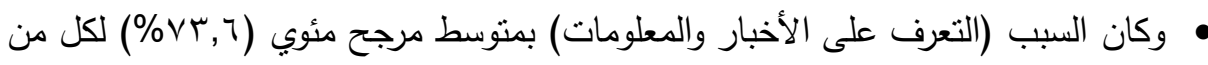

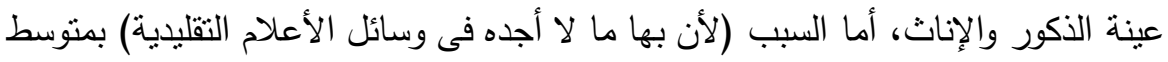

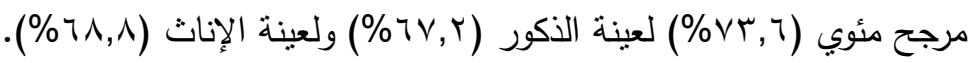

التساؤل الثانى: ما هى أهم مواقع التواصل الاجتماعي من وجهة نظر المراهقين؟

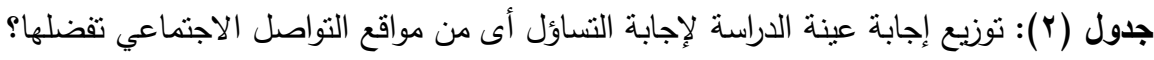

\begin{tabular}{|c|c|c|c|c|c|c|c|c|c|c|c|c|c|c|c|c|c|c|c|c|c|}
\hline \multicolumn{4}{|c|}{ بأز } & \multicolumn{4}{|c|}{ مجذ بلا } & \multicolumn{2}{|c|}{ قسنجزلر } & \multicolumn{3}{|c|}{4} & \multicolumn{2}{|c|}{4} & \multicolumn{3}{|c|}{ 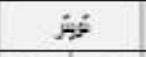 } & \multicolumn{3}{|c|}{ تجبربs } & \multirow{3}{*}{ هرتَ } \\
\hline 20 & is & 206 & at: & 4 & أئرل & & si & 30 & iكئز & 30 & & 6 & da & 6 & & 20 & i is & 20 & & is & \\
\hline$\%$ & I & $\%$ & $t$ & & 2 & $\%$ & I & $\% a$ & $\% a$ & $8 \%$ & a $\%$ & $t$ & $\%$ & $\%$ & I $\%$ & d & $\% t$ & $n$ & $2 \%$ & 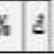 & \\
\hline if & A. & 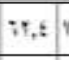 & $4 \lambda$ & t & 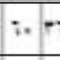 & $7, x=$ & 4 & \begin{tabular}{l|l|}
2,7 & $y$ \\
\end{tabular} & $5:$ & $=1,8$ & \begin{tabular}{l|l} 
& $+\lambda$ \\
\end{tabular} & (1) & $2,3 x$ & $t, A$ & $\therefore$ : & 70 & 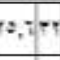 & 5 & $=1$. &. & $E$ \\
\hline$\cdot A$ & 1 & $\cdot \lambda$ & ' & - & 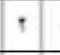 & 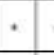 & & T. & & & L & $r+4$ & 5 & A. & $11 \cdot, \lambda$ & 4 & $A 1$ & $\pi$ : & $:=: 2$, & $\pi$ or & ํㅐ \\
\hline . & . & $=$ & $=$ & & . & ", & & $4,4 \pi$ & $17 \%$ & & $: 8$ & $\pi v$ & & $t$ & & 14 & $1,7 \%$ & ז & & $t, i \pm r$ & לे \\
\hline . &. & L & . & & & & & & $4:$ & & $19 \times 5,7$ & $n r y$ & $1+, \lambda 1$ & A & 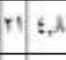 & a: & 1,87 & $\pi, t$ & &,$\lambda 17$ & $=1$ \\
\hline & 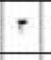 & 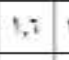 & , & & - & - & 1.1 & $t,: 4 \mathrm{~W}$ & $n, 1$ & $y=2,8$ & \begin{tabular}{|l|l}
$y$ & $f$ \\
\end{tabular} & & & $\theta$ & & & $x+1$ & 0,7 & \begin{tabular}{l|l}
$y$ & $t$, \\
\end{tabular} & .4 & $\rightarrow$ \\
\hline,$A$ & 4 & 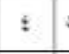 & $=$ & 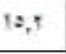 & 191 & & $18:$ & & & - &.$r$ & $7:$ & $|r, i\rangle$ & + 4,8 & $1+:=, d$ & $A=1$ & 8.2. & $r, T$ & $\$ \cdot, A$ & ${ }_{A} 1$ & ये \\
\hline 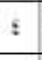 & 1 & 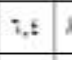 & " & & $r 2$ & 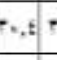 & +1 & \begin{tabular}{l|l|}
$\cdot, \lambda$ & 1 \\
\end{tabular} & \begin{tabular}{l|l}
$, A, A$ \\
\end{tabular} & 1,8 & $T \cdot \cdot \lambda$ & 11 & $t, t=7$ & $r$ & $\pm 1 \cdot$, & $=10$ & $8, \pi, 1$ &. &.$\quad$. &. & - \\
\hline & +2 & $18,5 \times$ & $\pi$ & & $1:$ &, $\pm A$ & i &. & \begin{tabular}{c|c|}
$\cdot, A$ & 1 \\
\end{tabular} & 1. & 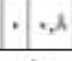 & & . &. & . 7, & 5 & $5=$ &,$A$ & 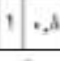 & $A 1$ & 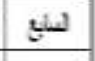 \\
\hline & $\varepsilon$ & & & & 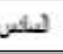 & & & - & & & مأب & & & ريب & & 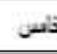 & & & dis & & ترنب \\
\hline
\end{tabular}

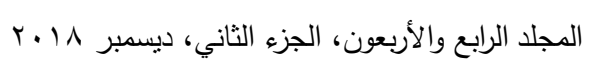


يثير الجدول السابق لإجابة عينة الدراسة على التساؤل "أى من مواقع التواصل الاجتماعي تفضلها؟" ما يلي: جاء في الترتبب الأول (الفيسبوك) أجاب أفراد العينة (الأول)

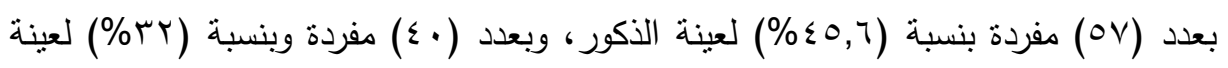

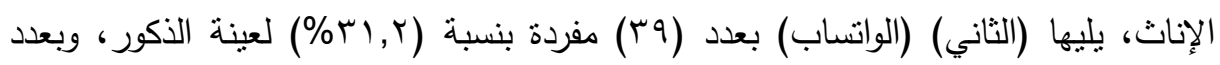

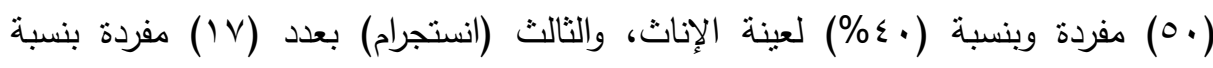

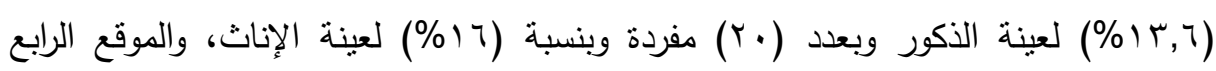

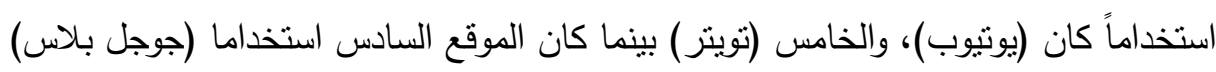
وأخيرا كان (ماي سيبس). التساؤل الثالث: هل توجد فروق بين المراهقين ( الذكور والإناث ) فى دوافع استخدام مواقع

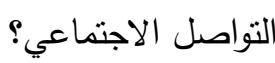
جدول (ب): اختبار (ت) لتوضيح الفروق بين المراهقين (الذكور والإناث) فى دوافع استخدام

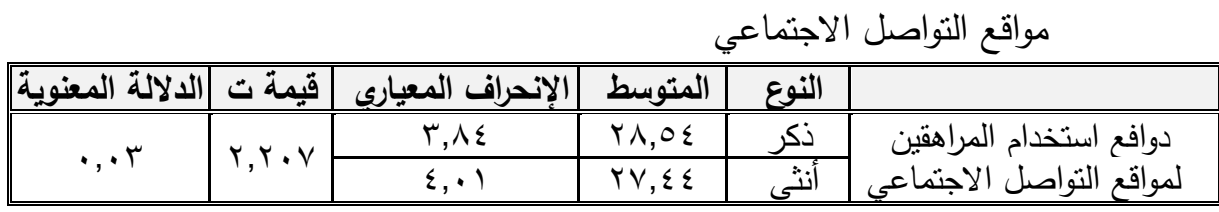

أنشارت نتائج الدراسة إلى وجود فروق ذو دلاعلة إلى إحصائية بين المراهقين الذكور والإناث

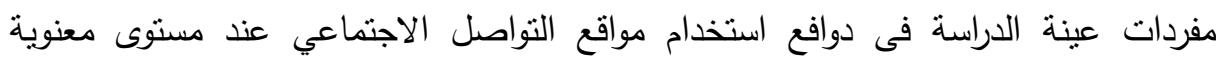

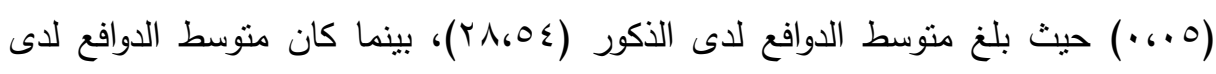

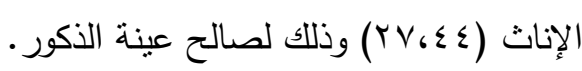
التساؤل الرابع: هل توجد فروق بين المراهقين (الذكور والإناث) فى طبيعة المواقع التى على يتعاملون معها؟ 
جدول (ء): اختبار (ت) لتوضيح الفروق بين (الذكور والإناث) فى طبيعة المواقع التى

\begin{tabular}{|c|c|c|c|c|c|}
\hline & & & \multicolumn{3}{|c|}{ يتعاملون معها } \\
\hline الالالة المغنوية & قيمة ت ت & الإنحراف المعياري & المتوسط & النوع & المواقع \\
\hline \multirow{2}{*}{$\cdot, \cdot \varepsilon$} & \multirow{2}{*}{$r, 1 \cdot V$} &., 97 & $1, \vee \wedge$ & ذكر & \multirow{2}{*}{ الفيسبوك } \\
\hline & & 1,19 & $r, \cdot V$ & أنثى & \\
\hline \multirow{2}{*}{$\cdot, 0$} & \multirow{2}{*}{$\cdot, T \cdot r$} & $r, r$. & $r, \pi r$ & ذكر & \multirow{2}{*}{ تويتز } \\
\hline & & $r, 1$. & $r, \vee \wedge$ & أنثي & \\
\hline \multirow{2}{*}{$\cdot, \Sigma$} & \multirow{2}{*}{$\cdot, \wedge \vee V$} & $1, \xi 1$ & r,Yo & ذكر & \multirow{2}{*}{ يوتيوب } \\
\hline & & $1, \varepsilon \wedge$ & $r, \Sigma 1$ & أنثي & \\
\hline \multirow{2}{*}{$\cdot, \cdot r$} & \multirow{2}{*}{$r, r V \leq$} & $1,1 \mathrm{~V}$ & T,YY & ذكر & \multirow{2}{*}{ وانتساب } \\
\hline & & $1, .0$ & 1,9 & أنثى & \\
\hline \multirow{2}{*}{., .0} & \multirow{2}{*}{$r, \cdot 11$} & $1, \Gamma \wedge$ & $r, q r$ & ذكر & \multirow{2}{*}{ انستجرام } \\
\hline & & $1, Y T$ & $r, 09$ & أنثي & \\
\hline \multirow{2}{*}{$\cdot, 1$} & \multirow{2}{*}{ (זיז } & $Y, V I$ & $r, r \mu$ & ذكر & \multirow{2}{*}{ جوجل بلاس } \\
\hline & & $r, \wedge$. & $r, V T$ & أنثي & \\
\hline \multirow[b]{2}{*}{$\cdot, 7$} & \multirow{2}{*}{$\cdot, 00 r$} & $r, 9 V$ & $r, I T$ & ذكر & \multirow[b]{2}{*}{ ماي سبيس } \\
\hline & & $r, r Y$ & T,TS & أنثى & \\
\hline
\end{tabular}

يتبين من الجدول السابق للفروق بين (الذكور والإناث) فى طبيعة المواقع التى يتعاملون معها وجود فروق ذو دلالة إحصائية بين (الذكور والإناث) عند مستوى معنوية (0.,.•) لكل

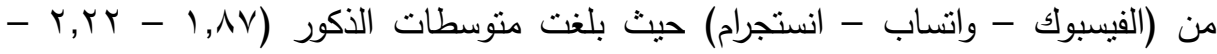

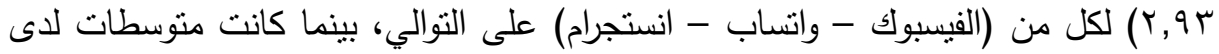

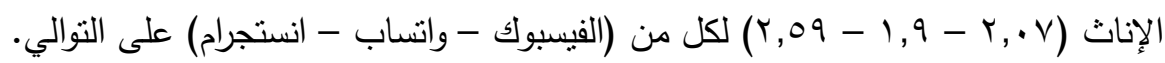
التساؤل الخامس: ما هى الانعكاسات الإجتماعية البيئية الناتجة عن استخدام المراهقين

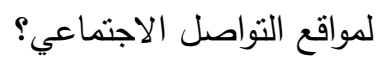


جلول (•): توزيع عينة الدراسة تبعا لأهم الانعكاسات الاجتماعيه الايجابية الناتجة من

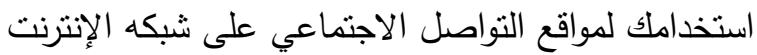

\begin{tabular}{|c|c|c|c|c|c|c|c|c|c|c|c|c|c|c|}
\hline \multirow{3}{*}{ |المتوسيط } & \multicolumn{6}{|c|}{ إناث } & \multirow{3}{*}{ |المتوسط } & \multicolumn{6}{|c|}{ ذكور } & \multirow{3}{*}{ الاناجعكاسات الايجابيه } \\
\hline & \multicolumn{2}{|c|}{ نعم } & \multicolumn{2}{|c|}{ أحيانا } & \multicolumn{2}{|l|}{$y$} & & \multicolumn{2}{|c|}{ نعم } & \multicolumn{2}{|c|}{ أحيانا } & \multicolumn{2}{|c|}{$\bar{y}$} & \\
\hline & $\%$ & s & $\%$ & ك & $\%$ & ك & & $\%$ & ك & $\%$ & ك & $\%$ & ك & \\
\hline $0 \wedge$ & $\varepsilon V, Y$ & 09 & re, $\varepsilon$ & $\leqslant r$ & $1 \wedge, \varepsilon$ & $r \mu$ & VA & $V 1, Y$ & 19 & $1 \%, 7$ & IV & $10, r$ & 19 & التحدث بحريه دون \\
\hline $0 \leqslant$ & $\wedge \cdot, \wedge$ & $1 \cdot 1$ & $1 \pi, 7$ & IV & 0,7 & $v$ & $\vee 9,7$ & $v 1, r$ & 19 & 17,1 & Yr & Kr & 10 & 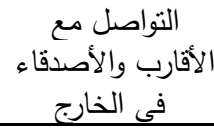 \\
\hline $01, r$ & $\sum 9,7$ & $\pi$ & $|r \uparrow, \varepsilon|$ & |r & $r \varepsilon$ & $r$. & $v 1,7$ & 7. & vo & $r \Gamma, Y$ & rq & $17, \lambda \mid$ & YI & تكوين صداقات \\
\hline 01,7 & $\Lambda \varepsilon$ & 1.0 & 9,7 & IT & $7, \varepsilon$ & $\Lambda$ & $\Lambda T$ & $\vee \wedge, \varepsilon$ & 91 & $10, r$ & 19 & $7, \varepsilon$ & $\Lambda$ & تمضية وقت الفراغ \\
\hline $70, r$ & or, 7 & $7 V$ & $\lceil\wedge, \varepsilon$ & $\leqslant \wedge$ & $\wedge$ & $1 \cdot$ & 79,7 & 07 & $v \cdot$ & $r V, r$ & $r \varepsilon$ & $17, \wedge$ & rI & بادة الرصيد الثقافى \\
\hline$O V, Y$ & $77, \varepsilon$ & Ar & $r \varepsilon$ & $r \cdot$ & 9,7 & Ir & $7 \wedge, \wedge$ & $0 \wedge, \varepsilon$ & $V T$ & $r \cdot, \Lambda$ & YT & $r \cdot, \lambda \mid$ & $r 7$ & الأخبار أولا بأولى \\
\hline or & or,, 1 & 77 & $r_{0,7}$ & rr & $r 1,7$ & $r v$ & 77 & $\varepsilon 9,7$ & Tr & $r, \Lambda$ & ॥1 & $\mid V, T$ & rr & شتعرف على ثنافات \\
\hline$\varepsilon \cdot, \wedge$ & $r \wedge, \wedge$ & 4 & $r 7, \varepsilon$ & | ( ) & $\varepsilon \varepsilon, \wedge$ & 07 & ov, 7 & $\leqslant \wedge$ & 7. & $1 \wedge, r$ & $r \varepsilon$ & $r \mathrm{r}, \Lambda$ & $\leqslant 1$ & $\begin{array}{c}\text { الأشتراك فى بعضات (اون } \\
\text { الأين } \\
\text { الكورسن }\end{array}$ \\
\hline
\end{tabular}

يشير الجدول السابق إلى أهم الانعكاسات الاجتماعيه الايجابية الناتجة من استخدامك

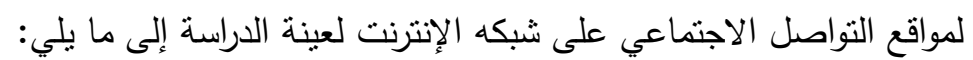

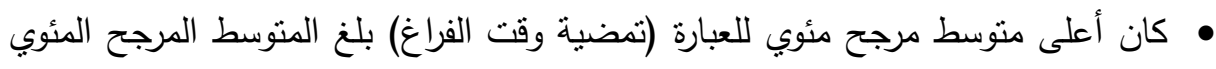

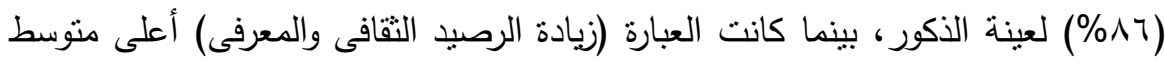

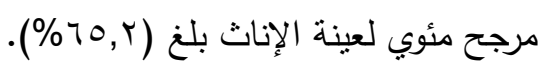

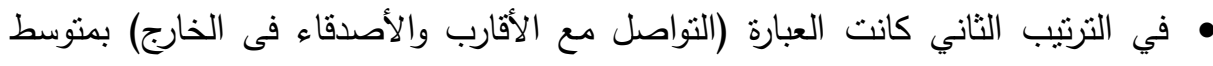

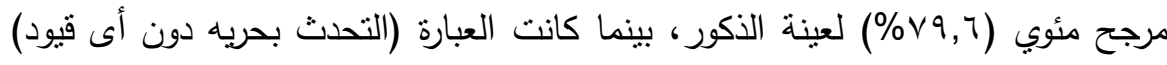

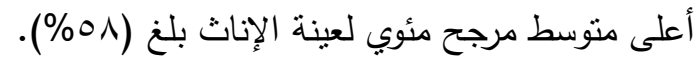




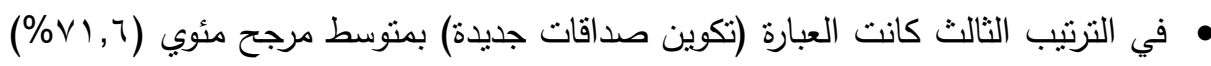

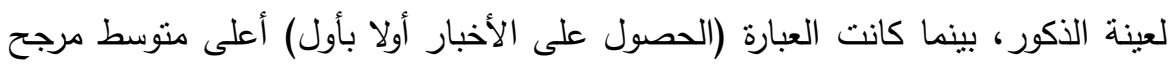

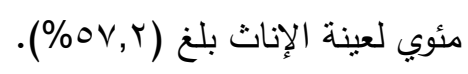

م وتفاوت المتوسط المرجح المئوي لباقي العبارات لعينتي الدراسة من الذكور والإناث ولكنها

تثتير لموافقتهم على تلك العبارات.

• وتم رفض العبارة من قبل عينة الإناث (الاثشراك فى بعض الكورسات (اون لاين))

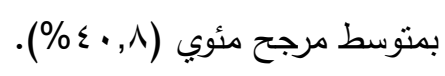

جدول (†): توزيع عينة الدراسة تبعاً للأنعكاسات الاجتماعية السلبية الناتجة من استخدامك

\begin{tabular}{|c|c|c|c|c|c|c|c|c|c|c|c|c|c|c|}
\hline \multirow{3}{*}{ المرئوي |المتوبي } & \multicolumn{6}{|c|}{ إناث } & | ل المتوسط| & \multicolumn{6}{|c|}{ ذكور } & \multirow{3}{*}{ الانعكاسات الاجتماعيه } \\
\hline & \multicolumn{2}{|c|}{ 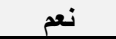 } & \multicolumn{2}{|c|}{ أحيانا } & \multicolumn{2}{|c|}{ ע } & \multirow{2}{*}{ |المرجح } & \multicolumn{2}{|c|}{ نمع } & \multicolumn{2}{|c|}{ أحيانا } & \multicolumn{2}{|c|}{ ע } & \\
\hline & $\%$ & ك & $\%$ & ك & $\%$ & 5 & & $\%$ & ك & $\%$ & 5 & $\%$ & ك & \\
\hline or, r & $0 ., \Sigma$ & 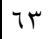 & rᄉ & o & 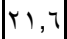 & rV & - & - & - & - & - & - & - & أهدار الوقت \\
\hline$\varepsilon\rceil, \wedge$ & r, & $\leqslant 1$ & $\Gamma \cdot, \varepsilon$ & T人 & $r$ & $\leqslant 7$ & $01, Y$ & $\varepsilon$. & 0. & $r Y, \Sigma$ & rᄉ & $r v, \tau$ & $\varepsilon V$ & إهمال بعض الواجبات \\
\hline$\varepsilon r, 7$ & $r \varepsilon, \wedge$ & ו & r T, & rq & $\varepsilon \varepsilon$ & 00 & $\leqslant 7$ & r, & $\leqslant 1$ & $r\urcorner, \Sigma$ & | - ( & $\varepsilon \cdot, \wedge$ & 01 & عدم الأهتمام بشئون الأسرة \\
\hline$r, r$ & $r \cdot, \Lambda$ & ry & $r \cdot, \wedge$ & YT & $0 \wedge, \Sigma$ & $\mathrm{Vr}$ & rч, & $Y \varepsilon$ & r. & $r \varepsilon, \wedge$ & M & $01, Y$ & $T \varepsilon$ & عدم الأهتمام بالحضور فى العنائليه \\
\hline$\varepsilon r, \wedge$ & $r \tau, \varepsilon$ & 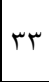 & rq, & re & $\varepsilon \varepsilon$ & 00 & $\leqslant\rceil, \leqslant$ & דץ & $\leqslant 0$ & $r \cdot, \Lambda$ & rt & $\varepsilon r, r$ & $0 \leqslant$ & عدم التعاون في أداء الأعمال \\
\hline$r q, \varepsilon$ & די & $\leqslant 0$ & $1 \wedge, \varepsilon$ & rtr & $\leqslant 0,7$ & ov & $\varepsilon q, r$ & $r 9, r$ & $\leqslant 9$ & $r$. & ro & $\varepsilon \cdot, \wedge$ & 01 & نسبب بعض المشكلات الصحية. \\
\hline$\leqslant Y, \wedge$ & $\varepsilon V, r$ & 09 & $19, Y$ & Ts & 童 & $\leqslant Y$ & $\leq 9, r$ & \&1,7 & or & $10, r$ & 19 & $\varepsilon r, Y$ & of & سبب فى أضعاف اللغه العربيه \\
\hline $0, \varepsilon$ & $\leqslant 9,7$ & Tr & Yo,, 1 & rt & $r \leq \leq, \wedge$ & M & $0 \wedge$ & $\leqslant 7, \varepsilon$ & $0 \wedge$ & rT, & rq & $r \cdot, \varepsilon$ & T人 & 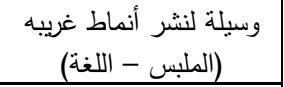 \\
\hline 0 . & $\varepsilon \cdot, \wedge$ & 01 & Yq, T & rv & r १, & re & $0 \wedge$ & $\varepsilon\rceil, \varepsilon$ & $0 \wedge$ & r & rq & $r \cdot, \Sigma$ & r & زيادة العزلة الاجتماعيه \\
\hline$\varepsilon \varepsilon$ & $r 0, r$ & $\varepsilon \varepsilon$ & YY, \& & rr & $\mu \wedge, \Sigma$ & $\leqslant \wedge$ & $\leqslant r$ & $r$ r,A & «1 & $1 \wedge, \Sigma$ & Tr & $\leq \wedge, \wedge$ & 71 & ضعف العلاقات الأسرية \\
\hline 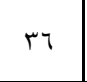 & 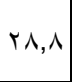 & דr & Y I, T & tr & $\leqslant 9,7$ & Tr & $r v, r$ & Yo,, 1 & rt & r & rq & $01, Y$ & $7 \varepsilon$ & أشعر بالنوتر عند عدم استخدامى للمواقع \\
\hline$\varepsilon r, \varepsilon$ & $r V, r$ & rs & $\curlyvee \wedge, \wedge$ & די & $\varepsilon \varepsilon$ & 00 & $\varepsilon r$ & $Y V, r$ & T纟 & $r q, 7$ & re & $\varepsilon r, Y$ & of & إهمال ممارسه الشعائر الدينية \\
\hline$\varepsilon 0, r$ & $r q, r$ & $\leqslant 9$ & Yo, T & rt & $r 0, r$ & $\varepsilon \varepsilon$ & 7. & $\varepsilon \wedge, \wedge$ & 71 & $r, V$ & rs & $\curlyvee \wedge, \wedge$ & די & إهمال القراءة والأطلاع على الكتب \\
\hline$\varepsilon \varepsilon, \varepsilon$ & $\varepsilon r, \varepsilon$ & or & $r r, r$ & rq & $r \varepsilon, \varepsilon$ & $\leqslant r$ & 00,7 & $\varepsilon$. & 0. & r & rq & $r \wedge, \wedge \mid$ & דו & تساهم فى إنتشار بعض الغير مرغوبه \\
\hline
\end{tabular}

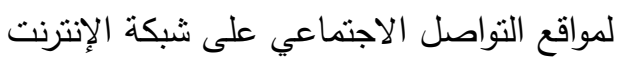

$$
\text { المجلد الرابع والأربعون، الجزء الثاني، ديسمبر 1 1 ـ ب }
$$


يشير الجدول السابق إلى أهم الانعكاسات الاجتماعيه السلبية الناتجة من استخدامك

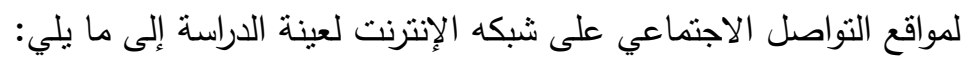

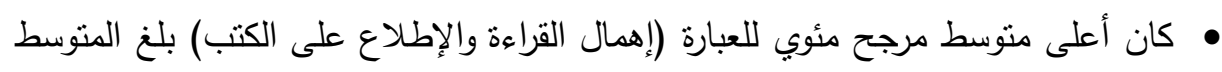

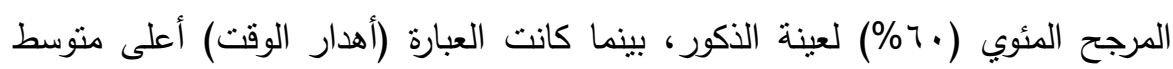

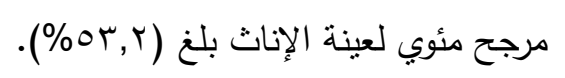

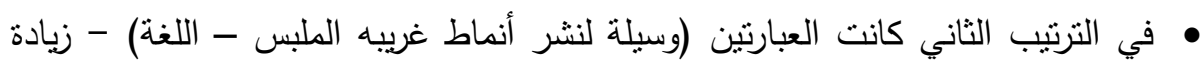

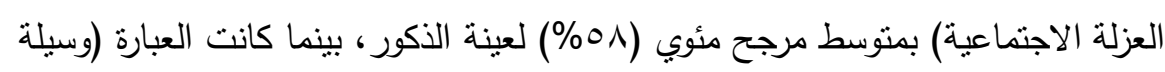

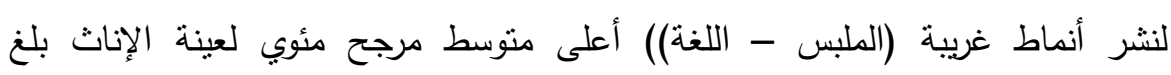
$\cdot(\% 0 \cdot, \varepsilon)$ • في الترتيب الثالث كانت العبارة (تساهم فى إنتشار بعض السلوكيات الغير مرغوبه)

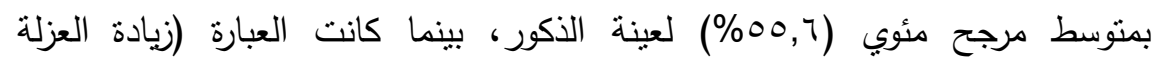

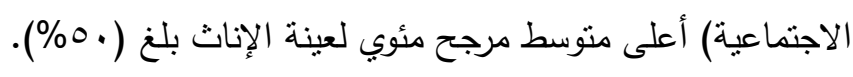

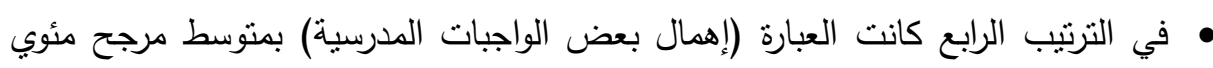

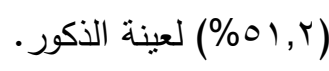
• ونت رفض باقي العبارات من قبل عينتي الذكور والإناث بمتوسط مرجح مئوي نراوح بين

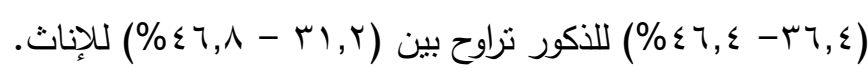


جدول (V): نوزيع عينة الدراسة تبعاً للأنعكاسات البيئية من وجهه نظرك الناتجة عن

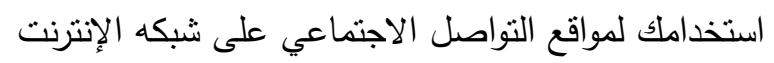

\begin{tabular}{|c|c|c|c|c|c|c|c|c|c|c|c|c|c|c|}
\hline | المتوسط & \multicolumn{6}{|c|}{ إناث } & | المتوسي & \multicolumn{6}{|c|}{ ذكور } & \multirow{3}{*}{ الانعكاسات البيئية } \\
\hline | المرجح & \multicolumn{2}{|c|}{ نعم } & \multicolumn{2}{|c|}{ أحيانا } & \multicolumn{2}{|c|}{ ע } & \multirow{2}{*}{ | المئويج } & \multicolumn{2}{|c|}{ ن معم } & \multicolumn{2}{|c|}{ أحيانا } & \multicolumn{2}{|c|}{ ע } & \\
\hline المئوي & $\%$ & st & $\%$ & S| & $\%$ & (5) & & $\%$ & ك) & $\%$ & ك & $\%$ & (5) & \\
\hline $07, \Lambda$ & $\varepsilon$. & 0. & ד, זין & $\leq Y$ & $|r q, \varepsilon|$ & | & 77 & Or & 70 & YA & ro & $r \cdot$ & ro & تزيد المعرفة بتاريخ مصر \\
\hline$V O, Y$ & $7 \leqslant$ & $\Lambda$. & rr, & 시 & $|r, 7|$ & IV & $\vee \vee, \wedge$ & 70,7 & $A Y$ & $r, Y$ & rᄉ & Ir & 10 & تزيد المعرفة بالقضايا والمشكلات \\
\hline$T r, \varepsilon$ & $\leqslant T, Y$ & $0 \leq$ & rᄉ, \& & $\leqslant \wedge$ & $1 \wedge, \Sigma$ & r & $77, \wedge$ & $07, \lambda$ & VI & $r \cdot$ & ro & $r r, r$ & ra & وسيله للمطالبة بالحقوق \\
\hline $77, \varepsilon$ & $\leqslant 0,7$ & $0 \mathrm{~V}$ & $\leqslant 1,7$ & or & $\mid r, \lambda$ & 17 & 79,7 & $00, r$ & 79 & $r \wedge, \wedge$ & דr & 17 & $r \cdot$ & وسبله لتوفير فرص عمل \\
\hline$V \varepsilon$ & $07, \wedge$ & V) & $r \leqslant, \varepsilon$ & $\leq \pi$ & $\wedge, \wedge$ & 111 & $\vee \vee \neg, \Sigma$ & $77, \varepsilon]$ & $\wedge r$ & r. & ro & $|\pi, 7|$ & IV & 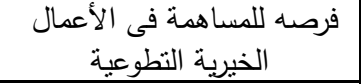 \\
\hline$\checkmark \wedge, \wedge$ & , ₹ & 71 & , & |דין & 17,1 & II & $\vee \varepsilon, \wedge$ & 1,7 & $V V$ & $1, \varepsilon$ & זr & Ir & 10 & معرفه أهم الظواهر البيئية فى أنحاء العالم \\
\hline $77, \varepsilon$ &,$Y$ & &,$\varepsilon$ & 시 & $|\wedge, \xi|$ & $|r \mu|$ & $7 \wedge, \wedge$ & 07,1 & $1 \times 1$ & $r \varepsilon$ & r. & 19,4 & $r \varepsilon$ & متابعه أهم الأخبار والقضايا \\
\hline $7 V, 7$ & or, 7 & $7 \mathrm{~V}$ & $r \wedge$ & ro & $1 \wedge, \Sigma$ & Th & $V T, Y$ & $7 \cdot, 1$ & 17 & $r \leq, \wedge$ & ו & $1 \leq, \leq$ & 11 & وسيله لترويج الثائعات \\
\hline 07 & $r, \lambda$ & $\leqslant 7$ & rᄉ, & $\leqslant 1$ & $r \leqslant, N$ & ו & 79,7 & $0 \wedge, \varepsilon$ & $V \mu$ & $r r, \varepsilon$ & Yर & 19,4 & $r \leq$ & تزيد من الحركات والأعنصامات \\
\hline $7 \cdot \wedge$ & $\varepsilon \varepsilon$ & 00 & 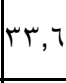 & $\leqslant Y$ & $|r, \varepsilon|$ & rN & $7 \wedge, \varepsilon$ & $00, Y$ & 19 & Y., \& & אוr & $1 \wedge, \varepsilon$ & r & نشر أنثكال جديده من الجرائم \\
\hline or,, r & $r, r$ & ra & $\varepsilon \varepsilon$ & 00 & $r \leqslant, \lambda$ & ו & ov, 7 & $\leqslant 1,7$ & $0 Y$ & r & $\varepsilon$. & $r 7, \Sigma$ & 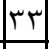 & سبب فى أنتشار الفوضى \\
\hline 79,7 & 4,1 & $1 \varepsilon$ & $r \cdot$, & rT & $r$. & ro & $7 \varepsilon, \Lambda$ & $0 \leqslant, \varepsilon$ & 71 & 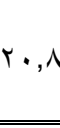 & Trat & $r \leqslant$, & | ו & 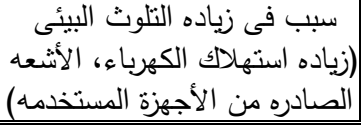 \\
\hline
\end{tabular}

يشير الجدول السابق إلى أهم الانعكاسات البيئية الناتجة من استخدامك لمواقع التواصل الاجتماعي على شبكه الإنترنت لعينة الدراسة إلى ما يلي: العئي:

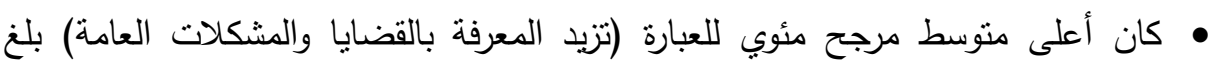

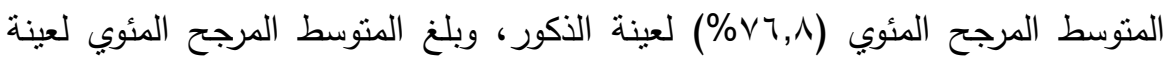

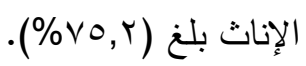

• في الترتيب الثاني كانت العبارة (فرصه للمساهمة فى الأعمال الخيرية التطوعية) بمتوسط

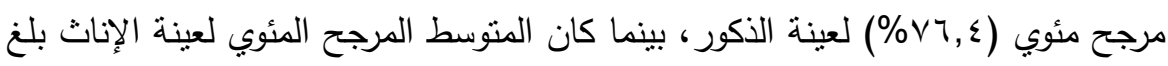


• في الترتيب الثالث كانت العبارة (معرفه أهم الظواهر البيئية فى مختلف أنحاء العالم)

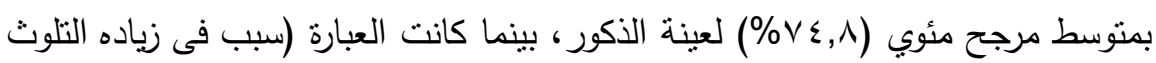

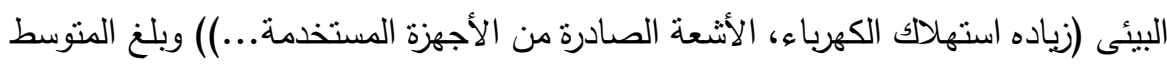

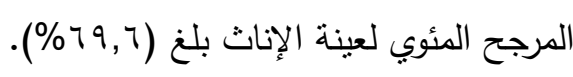

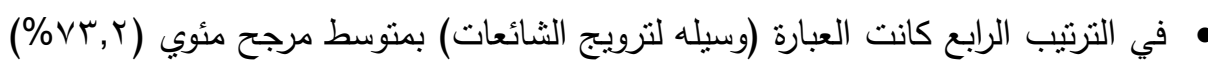

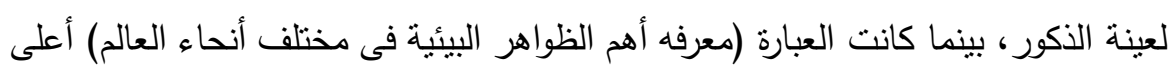

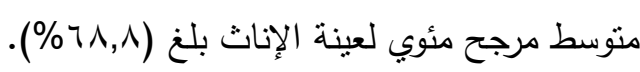
• ت ن رفض باقي العبارات من قبل عينتي الذكور والإناث بمنوسط مرجح مئوي نراوح بين

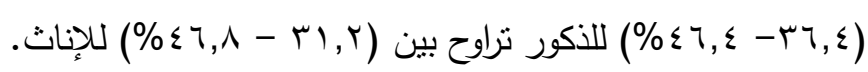

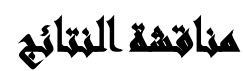

توصلت الدراسة الراهنة لمجموعة من النتائج وذلك من خلال الإجابة على تساؤلات الدراسة: التساؤل الأول: ما هى دوافع استخدام المراهقين لمواقع التواصل الاجتماعي؟ لؤه

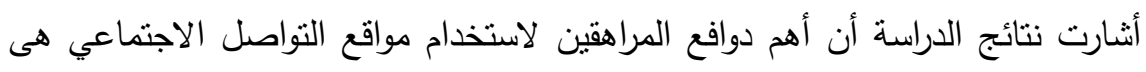
على التوالى التسلية والترفيه، التعرف على كل ما هو جديد، مشاهدة الصور والأفلام والمسلسلات والأغانى، التخلص من الملل وشغل أوقات الفراغ، التعرف على على الأخبار والمعلومات، لأن بها ما لا أجدة فى وسائل الإعلام التقليدية.

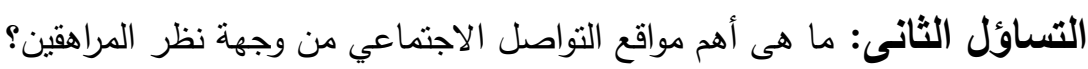

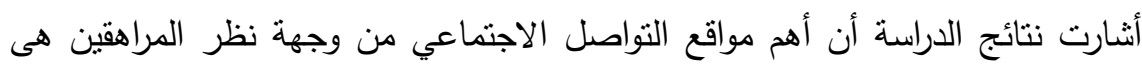

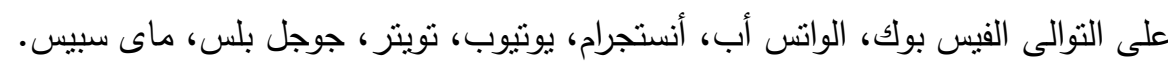

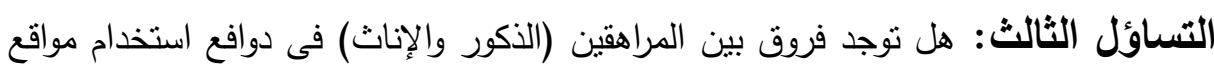

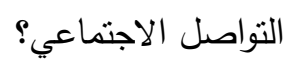
أثنارت نتائج الدراسة إلى وجود فروق ذو دلالة إحصائية بين المراهقين الذكور والإناث

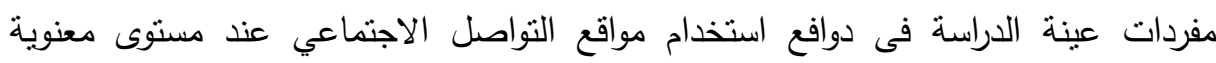




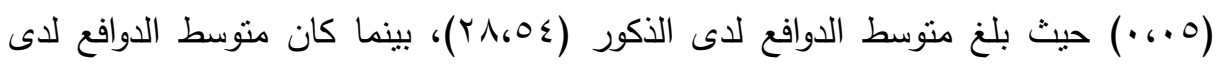

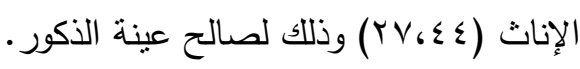
التشاؤل الرابع: هل توجد فروق بين المراهقين (الذكور والإناث) فى طبيعة المواقع التى ودئ يتعاملون معها؟ أثارت نتائج الدراسة إلى وجود فروق ذو دلالة إحصائية بين المراهقين الذكور والإناث

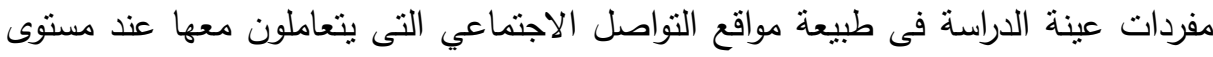
معنوية (0. ، • ) لكل من (الفيس بوك، الوانس أب، أنستجرام) التساؤل الخامس: هل توجد فروق بين المراهقين (الذكور والإناث) فى فترات استخدام مواقع التواصل الاجتماعي؟ أشارت نتائج الدراسة إلى وجود فروق بينّ الدراعين المراهين الذكور والإناث مفردات عينة الدراسة فى فترات استخدامهم لمواقع التواصل الاجتماعي. التساؤل السادس: ما هى الانعكاسات الإجتماعية البيئية الناتجة عن استخدام المراهقين لمواقع التواصل الاجتماعي؟ أثنارت نتائج الدراسة إلى العديد من الانعكاسات الناتجة عن استخدام المراهقين لمواقع التواصل الاجتماعي وتم تقسيمها كالتالى: الانعكاسات الإجتماعية الإيجابية: وكان من أهم الانعكاسات الإجتماعية الإيجابية الناتجة

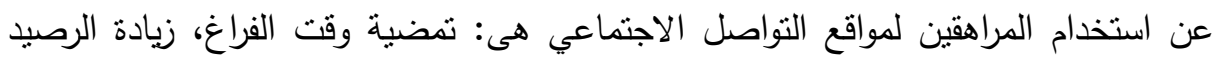

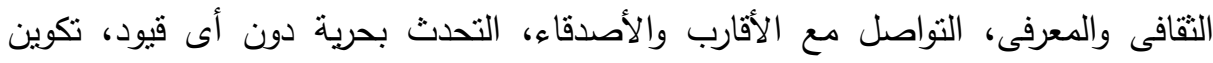
صداقات جديدة، الحصول على الأخبار أول بأول، التعرف على نقافات شعوب مختلفة.

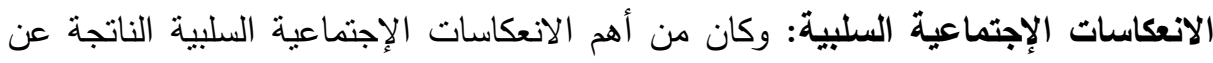

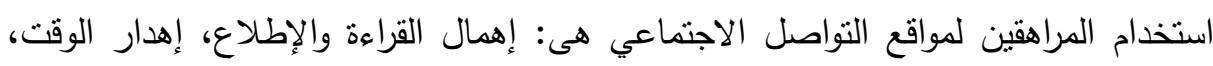

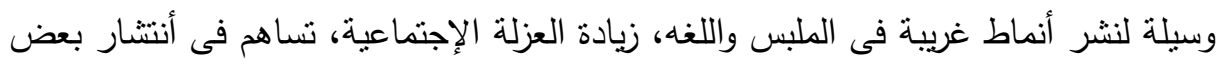
السلوكيات الغير مرغوبة، إهمال بعض الواجبات المدرسية. 
الانعكاسات البيئية الإيجابية: وكان من أهم الانعكاسات البيئية الإيجابية الناتجة عن استخدام

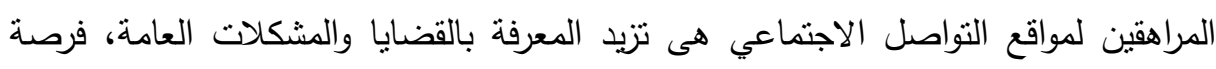

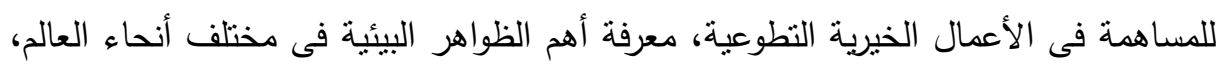

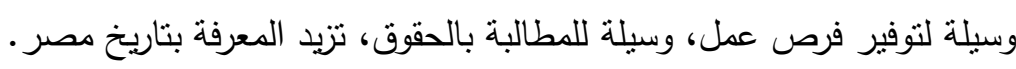

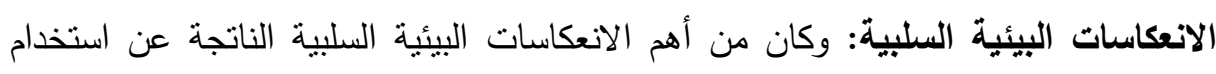

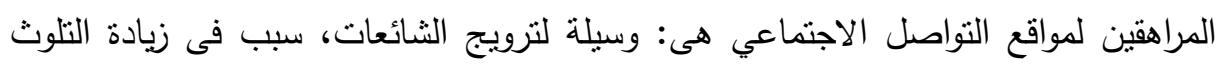

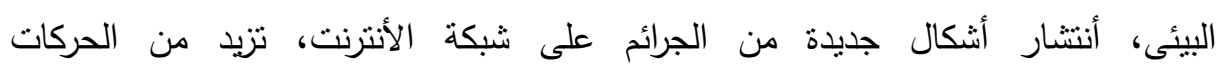

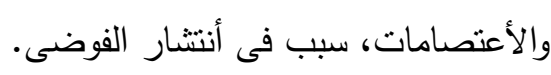
التساؤل السابع: ما هو الدور الذى تقوم به الأسرة مع المراهقين لمتابعة استخدامهم لمواقع

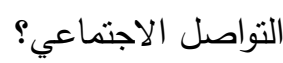
أثنارت الدراسة أن هناك بعض الأمور تقوم بها الأسر لمحاولة متابعة استخدام أبنائهم المراهقين لمواقع التواصل الاجتماعي ومنها: نسبة كبيرة من الوالدين والأخوة أصدقاء للمراهقين على مواقع التواصل الاجتماعي، بعض الأسر يتتاقشون مع الأبناء المراهقين حول إيجابيات

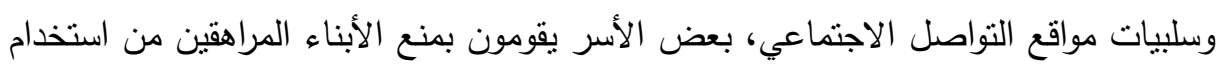

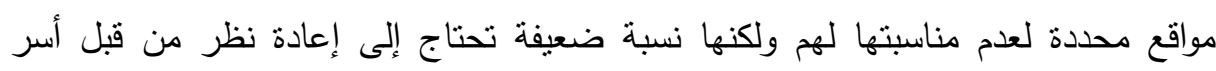

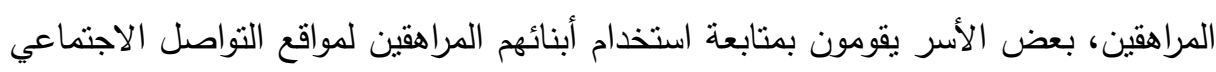
ويتفاعلون معهم من خلال تلك المواقع. التساؤل الثامن: ما هو التصور المقترح لمواجهة الانعكاسات السلبية الناتجة عن استخدام المراهقين لمواقع التواصل الاجتماعي؟ تم وضع تصور مقترح لمواجهة الانعكاسات السلبية الناتجة عن استخدام المراهقين

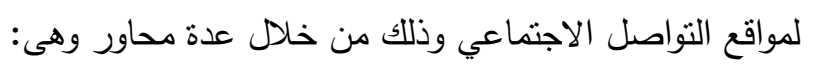
> ممارسة بعض الأنشطة الرياضية.

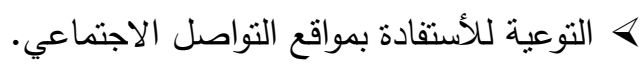
\& الأهتمام بتقوية الوازع الدينى والأخلاقى. ه أهتمام المدرسة بتفعيل الأنشطة الطلابية. 


\section{اللموكيايت}

ه أن يكون لأسر المراهقين دوراً أكبر فى حياه أبنائهم وذلك من خلال زيادة الوقت الذى أنى

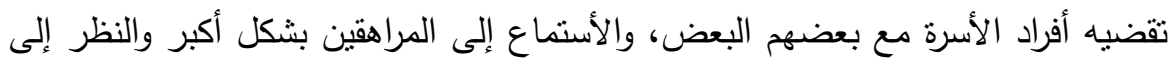
أحتياجاتهم ومحاوله حل مشكلاتهم، وأن يكون للمراهق صوت مسموع داخل أسرته بدلاًا

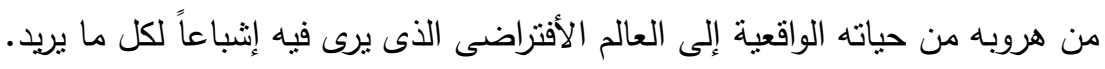

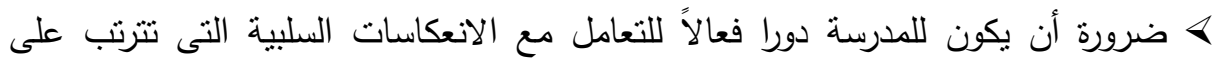
استخدام المراهقين لمواقع التواصل الاجتماعي وذلك من خلال عقد الندوات وورش العمل المختلفة التى تتتاول ايجابيات وسلبيات التعامل مع مواقع التواصل الاجتماعي، تقعيل الأنشطة الطلابية المفضله لدى المراهقين لجذبهم لممارسه أنشطه لشغل أوقات الفراغ بدانلا من تقضيه كافه الوقت فى التعامل مع مواقع التواصل الاجتماعي.

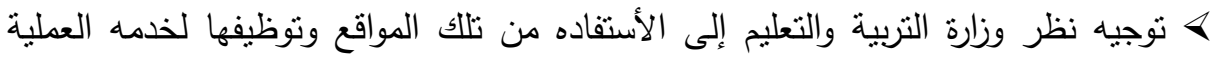

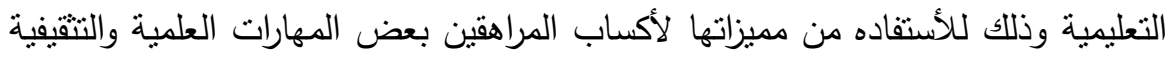
ومحاوله الحد من الانعكاسات السلبية الناتجة عن استخدامهم لهذه المواقع - سن لهن التشريعات والقوانين التى تسمح للأجهزة الرقابية بالتعامل مع هذه المواقع واستخدام سلطنها

$$
\text { فى منع المواقع الغير مناسبة. }
$$

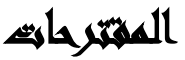

تشير الدراسة الحالية عددا من الموضوعات التى يمكن دراستها مستقبلا ومنها: كا تتاول دراسة مواقع التواصل الاجتماعي الجديدة التى ظهرت مؤخراً بخلاف (الفيس بوك اليوتيوب - تويتر ) ومعرفه تأثثراتها المختلفة. < دراسة شرائح مختلفة متل الأطفال فى مرحله الطفولة المتأخرة، الثباب الجامعى، الأسر، ، 
هـ دراسة الجانب الأيجابى لمواقع التواصل الاجتماعي فى تتميه المهارات الاجتماعيه والثقافية المختلفة وخاصة لاى المراهقين والثباب.

\section{2all}

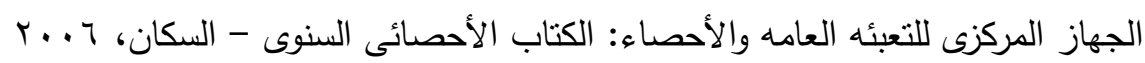

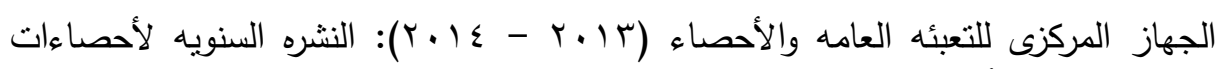

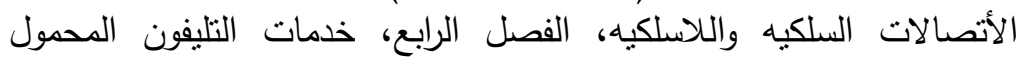
والأنترنت، القاهرة.

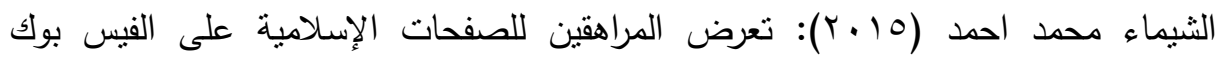

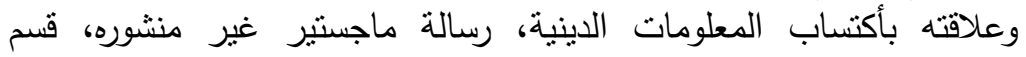

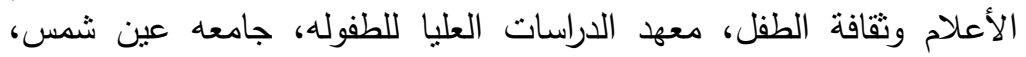

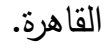

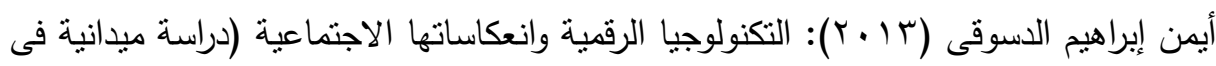

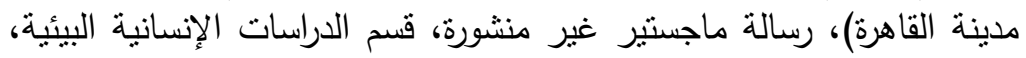
معهد الدراسات والبحوث البيئية، جامعة عين شمس، القاهرة.

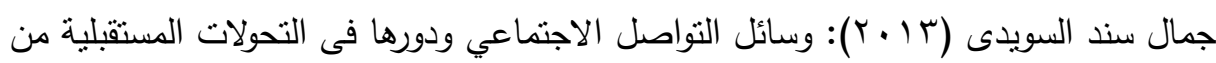
القبيلة إلى الفيسبوك، ب. ب.د.ن

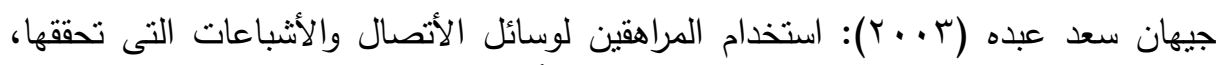

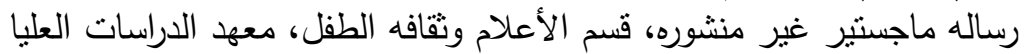
للطفوله، جامعه عين شمس، القاهرة.

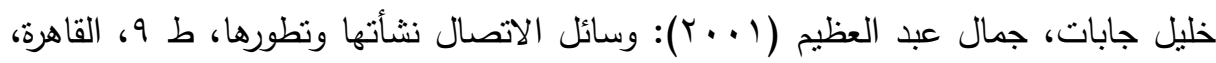

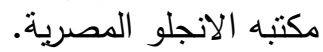

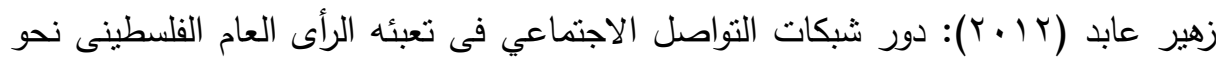

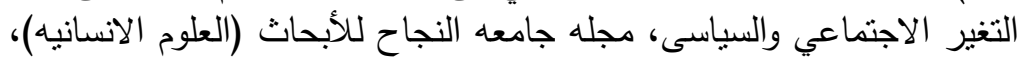

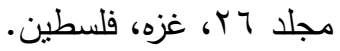

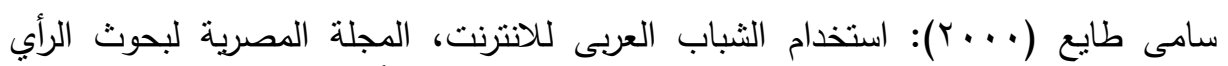

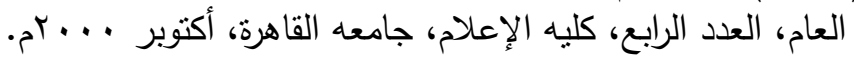


محمد عبد الحميد محمد (99VV) القاهرة: نظريات الأعلام واتجاهات التأثير، طا، عالم الكتب،

محمد قاسم عبد اله (10 ـ r): إدمان الإنترنت وعلاقته بسمات الشخصية المرضية لدى

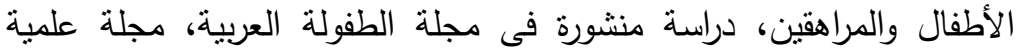

بحثية فصلية تصدرها الجمعية الكويتية لتقدم الطفولة العربية، المجلد 17 الكالة

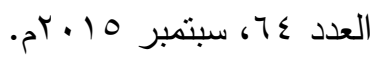

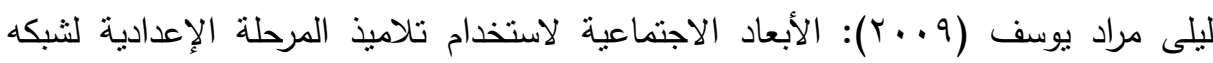

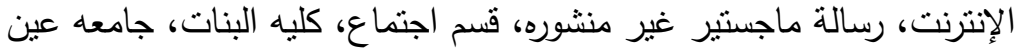

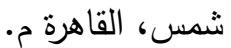

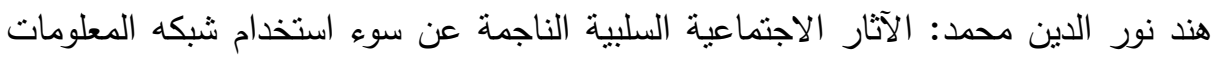

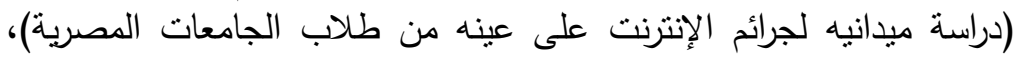

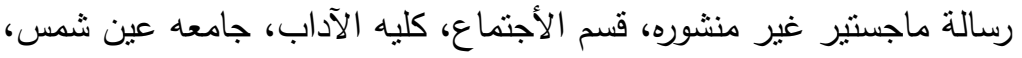

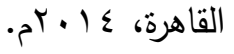

يوسف محمد محمد (10 • ب): النظريات النفسيه والاجتماعيه في وسائل الأتصال المعاصره

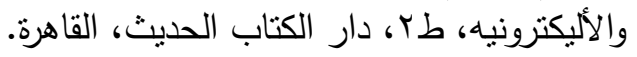

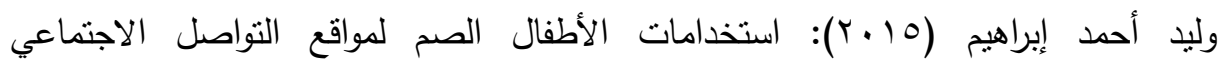

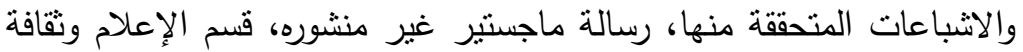
الطفل، معهد الدراسات العليا للطفولة، جامعه عين شمس.

Aaron H. Esman M. D. (1990): Adolescence and culture, Columbia University press New York Oxford.

Eric Gangon (1996): What's on the internet: The Definitive guide to the internet's use net news groups, $3^{\text {rd }}$ ed., USA: peach pit press.

Ikenna Adiele; Wole Olatokun (2014): Prevalence and Determinants of internet addiction among adolescents, Computers in human Behavior, vol: 31, issue.

James, Libba (2014): Continuing bonds in a virtual world: the use of facebook in adolescent grief, Ph.D, Colorado states University, United States.

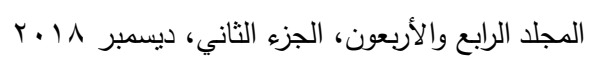


هبة صالح أبو سريع وآخرون

Tim, O., Sullivan, and others (1994): Key concept in communication and curltural studies, Rautledge, London.

\title{
A COMPARATIVE STUDY BETWEEN MALES AND FEMALES IN SOME LANGUAGES SCHOOLS
}

\author{
Heba, S. Abo Sereih ${ }^{(1)}$; Mostafa, M. Mahmoud ${ }^{(2)}$ \\ and Mohamed. M. Hassan ${ }^{(3)}$
}

1) Institute of Environmental Studies and Research, Ain Shams University 2) Faculty of Arts, Ain Shams University 3) The Higher Institute for Social Work

\begin{abstract}
Researchers seek across this research to identify mainly to the social as well as environmental reflections of the social media sites on adolescents; identifying as well the differences between males and females regarding their motives for using these sites and the most favorite sites and their different reflections. The study uses the descriptive-analytical method, using a questionnaire form as a tool for collecting data. The research counts on more than one theory to serve its topic which most important are: (Theory of Uses and GratificationsTheory of Maslow). The research sample consists of (250) items divided equally into males and females in addition to (15) items as subsample of experts in various fields and specialties.

The study comes to several results which most important re that there are statistically significant differences between males and females at (0.05) significance level regarding motives of use and there are also differences in nature of the sites they deal with and the time durations of use. Results indicate a set of social positive reflections reflected in spending luxury time, increasing cultural and cognitive outcome. The results have also monitored some negative reflections such as: neglecting reading and reviewing, wasting time, spreading out some

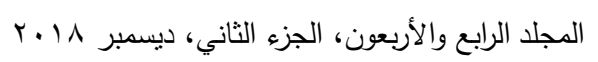


undesirable behaviors. The results report some positive environmental reflections exist like for instance, increasing knowledge about environmental issues and problems, identifying the most important environmental phenomena all over the world; while the negative environmental reflections are crystallized in that the social media sites have become a source of rumors and prevalence of a new form of crime that increase movements and stay-in strike.

The most important recommendations are reflected in that adolescent' families should have a bigger role in their children' lives by spending more time with them. An adolescent should be heard and understandable in his family. The school should also play an effective role in dealing with negative reflections through holding workshops, meetings, and symposiums for students, activating as well the preferable activities for students to spend their spare times in useful actions instead of dealing with the social media sites. 